Article

\title{
Investigations of Exhaust Emissions from a Combustion Engine under Simulated Actual Operating Conditions in Real Driving Emissions Test
}

\author{
Monika Andrych-Zalewska ${ }^{1, *(\mathbb{D})}$, Zdzislaw Chlopek ${ }^{2}$, Jerzy Merkisz ${ }^{3}(\mathbb{D})$ and Jacek Pielecha $^{3}(\mathbb{D})$ \\ 1 Faculty of Mechanical Engineering, Wroclaw University of Science and Technology, Wybrzeze \\ Wyspianskiego 27, 50-370 Wroclaw, Poland \\ 2 Faculty of Automotive and Construction Machinery Engineering, Warsaw University of Technology, \\ Narbutta 84, 02-524 Warsaw, Poland; zdzislaw.chlopek@pw.edu.pl \\ 3 Faculty of Civil and Transport Engineering, Poznan University of Technology, pl. M. Sklodowskiej-Curie 5, \\ 60-965 Poznan, Poland; jerzy.merkisz@put.poznan.pl (J.M.); jacek.pielecha@put.poznan.pl (J.P.) \\ * Correspondence: monika.andrych@pwr.edu.pl; Tel.: +48-71-3477918
}

Citation: Andrych-Zalewska, M.; Chlopek, Z.; Merkisz, J.; Pielecha, J. Investigations of Exhaust Emissions from a Combustion Engine under Simulated Actual Operating Conditions in Real Driving Emissions Test. Energies 2021, 14, 935. https:// doi.org/10.3390/en14040935

Academic Editor: Leonid Tartakovsky

Received: 16 January 2021

Accepted: 7 February 2021

Published: 10 February 2021

Publisher's Note: MDPI stays neutral with regard to jurisdictional claims in published maps and institutional affiliations.

Copyright: (C) 2021 by the authors. Licensee MDPI, Basel, Switzerland. This article is an open access article distributed under the terms and conditions of the Creative Commons Attribution (CC BY) license (https:// creativecommons.org/licenses/by/ $4.0 /)$.

\begin{abstract}
The paper describes the methodology of research of exhaust emissions from a combustion engine under engine states determined by the vehicle actual operation in the RDE test. The processes of quantities determining the vehicle motion and engine states have been recorded, along with the exhaust emission intensity. Based on the developed research methodology, zero-dimensional characteristics of the processes of the emission intensity have been determined under the conditions of urban, rural and motorway traffic, as well as in the entire test. The authors also determined the average specific distance exhaust emissions under the conditions of urban, rural and motorway traffic, as well as in the entire test. Based on the above results, the unique characteristics of the relation of the average specific distance emissions and the average vehicle speed have been obtained. The obtained characteristics may be used in the modeling of exhaust emissions from motor vehicles under actual traffic conditions. The authors also explored the sensitivity of the average specific distance emissions to the vehicle driving style.
\end{abstract}

Keywords: exhaust emissions; passenger cars; real driving emissions

\section{Introduction}

Actual operating conditions of a vehicle may significantly differ from the ones simulated on chassis dynamometers. For this reason, methods of testing under real driving conditions were introduced to the research procedure of the vehicle properties. One of these methods is RDE (Real Driving Emissions) [1-4]. The idea behind this research procedure is the purposeful, partial indeterminacy of the test conditions at a simultaneous imposition of a variety of requirements. This property makes the possibility of treating the vehicle speed in each of the tests as a stochastic process. Within each of the realizations, there exist fragments that vary in terms of properties that may be described with different zero-dimensional characteristics [5]. Investigating the properties of vehicles under actual traffic conditions and recording the quantities that describe these properties on a continuous basis allows for exploring their sensitivity to the traffic conditions. This knowledge is much more extensive compared to the averaged vehicle values, as is in the case of the homologation procedure.

Investigations of the vehicle properties in random traffic conditions does not have a long tradition, though, the knowledge of the uncertainty of the results of investigations under actual conditions is attractive and useful [6-8]. Chlopek and Laskowski [7] present the method of determining of the characteristics of the specific distance emissions from a combustion engine in the domain of average speed, based on the recording of results of the emission intensity from a single realization of the vehicle speed. For the determination 
of the characteristics, the Monte Carlo method was applied [9], based on the recorded quantities of the random process having random variables: the time of initiation and end of the process realization. This allowed for determining the entire characteristics based on a single realization of the driving test instead of testing the vehicle at various average speeds. Chlopek [8] presents the methods of synthesis of driving tests as a random process of the speed of a given spectrum density of the speed power. The realization of this procedure allows for determining the characteristics of random investigated quantities, e.g., probability density of the specific distance exhaust emissions.

In this paper the authors decided to limit the exhaust emission tests from a diesel engine to conditions corresponding to the operation of a passenger vehicle in urban, rural and motorway cycles.

Papers related to the RDE exhaust emission testing mainly contain results of the entire test [10-20]. Merkisz and Pielecha [17] compare the results of the specific distance exhaust emissions from a diesel engine from two tests: the first one was developed to simulate the NEDC (New European Driving Cycle) homologation test [4] and the second, the RDE (Real Driving Emissions) test. In their research, the authors carried out an evaluation of the sensitivity of the test results to the length of the test route. Kurtyka and Pielecha [14] presented the results of tests performed on two gasoline vehicles in terms of the zerodimensional characteristics of the vehicle speed process, inter alia, the product of vehicle speed and relative positive acceleration. Merkisz et al. [16] presented the results of PEMSbased investigations of exhaust emissions from non-road vehicles. Valverde [20] took on a metrological attempt in the exhaust emissions testing under actual operating conditions using the PEMS equipment. Czerwinski et al. [12] compared the results obtained for passenger vehicles with different PEMS equipment on a chassis dynamometer and on the road. In the report [13], the relations of the results obtained on the chassis dynamometer during a homologation procedure and in the RDE test were investigated. It was observed that, under actual operating conditions, the emission of particulate matter from diesel engines is greater compared to the tests performed on the chassis dynamometer. Lee and Filipi [15] proposed a procedure of a synthesis of actual driving cycles with a view to reproducing the actual driving conditions of a vehicle. The vehicle speed and acceleration were used as modeled with the Markov processes. However, there are no publications related to the exhaust emissions related to the dynamic states of the engines in driving tests under actual traffic conditions. The results presented in this paper pertain to this particular subject of exhaust emissions under dynamic states in actual RDE traffic conditions.

\section{Aim of the Research}

The aim of the research is the assessment of the sensitivity of the exhaust emissions from a diesel vehicle to its operating states determined by the vehicle speed on urban, rural and motorway road portions. The realization of the research scheme is to allow an assessment of this sensitivity under actual traffic conditions. It is purposeful to explore the properties of vehicle engines under the conditions of actual traffic, for which a certain indeterminacy of the speed process is characteristic.

The aim of the investigations is also the determination of the characteristics of exhaust emissions from combustion engines under the conditions of actual traffic. The characteristics determined in this way may be used in modeling the exhaust emissions on predefined routes and in the evaluation of the environmental impact of transport.

\section{Subject and Research Methods}

The object of the research was a Fiat Idea fitted with a 1.3 JTD MultiJet diesel engine. Table 1 presents the technical specifications of the engine. 
Table 1. Technical specifications of the engine (1.3 JTD MultiJet).

\begin{tabular}{lc}
\hline \multicolumn{1}{c}{ Name } & Specification \\
\hline type of ignition & auto-ignition \\
fuel feed & direct injection \\
displacement & $1300 \mathrm{~cm}^{3}$ \\
supercharging & in-line $4 / 8$ \\
number of cylinders/valves & turbocharger constant geometry \\
injections, maximum injection pressure & common rail, $140 \mathrm{MPa}$ \\
rated power output at rpm & $51 \mathrm{~kW} / 4000 \mathrm{~min}^{-1}$ \\
maximum torque at rpm & $180 \mathrm{~N} \cdot \mathrm{m} / 1750 \mathrm{~min}^{-1}$ \\
oxidation catalyst & yes \\
particulate filter & no \\
emission standard & Euro 4 \\
\hline
\end{tabular}

Figure 1 presents the object of the research with the installed equipment.

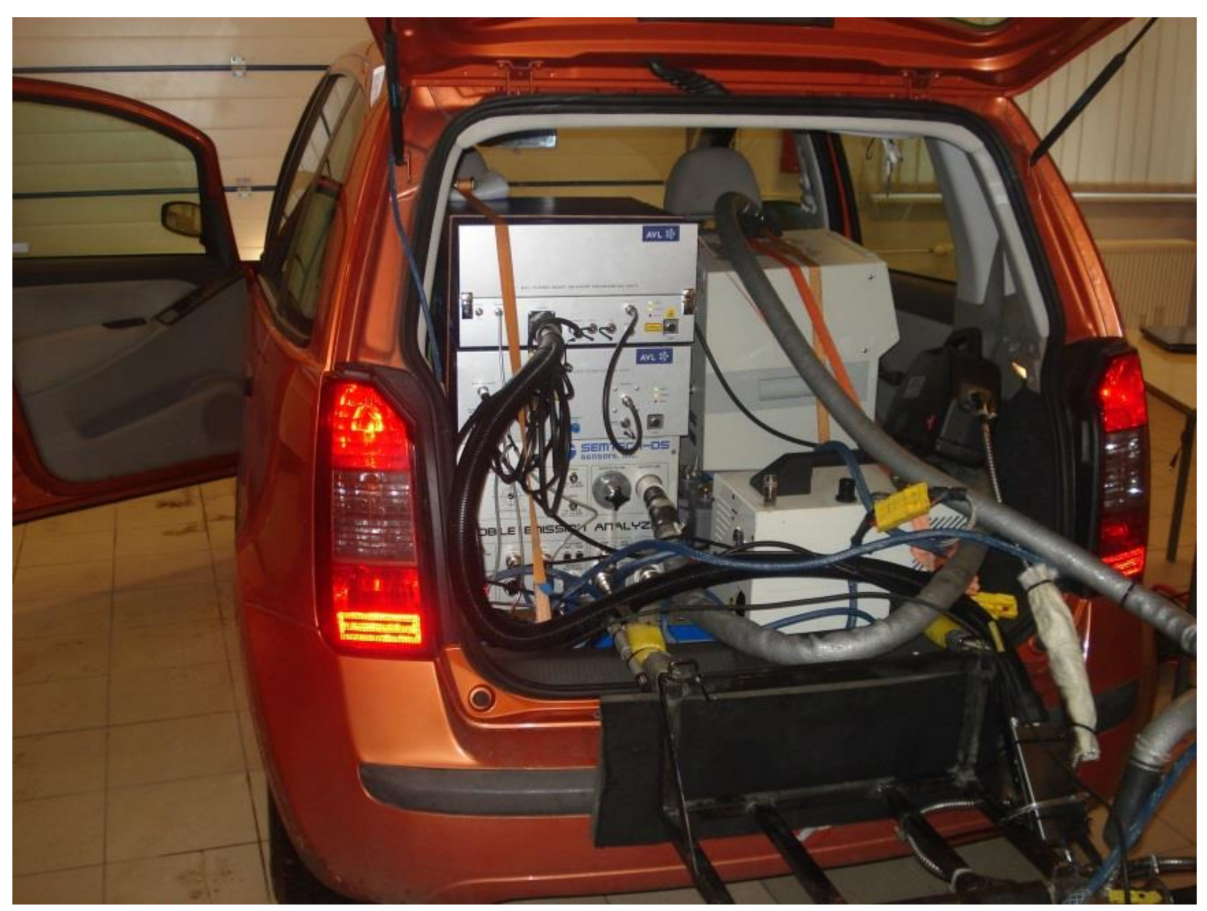

Figure 1. Fiat Idea with the testing equipment fitted.

The tests were carried out in the RDE regime. The test under actual traffic conditions covers the test runs in the urban and then rural and motorway portions. The test drive in the said portions is continuous. The test runs in the rural cycle may be interrupted by short portions of urban driving if they occur on the vehicle test route. The motorway cycle can also be interrupted by short urban or rural drives (toll plazas or road works). If, for practical reasons, a different order (urban, rural, motorway) of the test is substantiated, it can be modified upon the consent of the homologating authority.

The vehicle operation in the urban cycle is characterized by vehicle speeds not exceeding $60 \mathrm{~km} / \mathrm{h}$, in the rural cycle -60 to $90 \mathrm{~km} / \mathrm{h}$ and, in the motorway cycle, more than $90 \mathrm{~km} / \mathrm{h}$ (Table 2). The test route covers a share of $29-44 \%$ of the test in the urban portion, $23-43 \%$ in the rural portion and $23-43 \%$ in the motorway portion. The vehicle operation in the urban cycle must, however, include at least $29 \%$ of the entire test distance. The vehicle speed on the motorway does not usually exceed $145 \mathrm{~km} / \mathrm{h}$. The maximum speed can be exceeded by $15 \mathrm{~km} / \mathrm{h}$ for not longer than $3 \%$ of the duration of the motorway drive. During the RDE test, the local speed limits are in force, irrespective of other legal consequences. The excess of the local speed limits as such does not invalidate the test. 
The average driving speed (including the stops) in the urban area should fall in the range from 15 to $30 \mathrm{~km} / \mathrm{h}$. The stops, understood as time when the vehicle speed is less than $1 \mathrm{~km} / \mathrm{h}$, should constitute at least $10 \%$ of the time of operation in the urban cycle. The vehicle operation in the urban cycle includes several stops of at least $10 \mathrm{~s}$. A situation when a single stop occurs, covering more than $80 \%$ of the entire stop time in the urban cycle, should be avoided. The vehicle speed on the motorway must fall in the range from $90 \mathrm{~km} / \mathrm{h}$ to at least $110 \mathrm{~km} / \mathrm{h}$. The vehicle speed must exceed $100 \mathrm{~km} / \mathrm{h}$ for a minimum duration of $5 \mathrm{~min}$. The drive time must fall in the range from 90 to $120 \mathrm{~min}$. The test start and end points must not be different in terms of the elevation above the sea level by more than $100 \mathrm{~m}$. The minimum distance covered in the urban, rural and motorway cycles must be at least $16 \mathrm{~km}$ (detailed requirements provided in Table 2).

Table 2. RDE test run requirements.

\begin{tabular}{cccc}
\hline Requirements & Urban & Rural & Motorway \\
\hline speed & $(0-60) \mathrm{km} / \mathrm{h}$ & $(60-90) \mathrm{km} / \mathrm{h}$ & $>90 \mathrm{~km} / \mathrm{h}$ \\
distance & $\sim 34 \%( \pm 10 \%)$ & $\sim 33 \%( \pm 10 \%)$ & $\sim 33 \%( \pm 10 \%)$ \\
minimum distance & $16 \mathrm{~km}$ & $16 \mathrm{~km}$ & $16 \mathrm{~km}$ \\
share & $>29 \%$ & - & - \\
\hline
\end{tabular}

In addition, other detailed requirements must be met when carrying out the test $[1-3,21]$. These are related to:

- The weather conditions and thermal state of the vehicle;

- Topographic conditions of the test route;

- Driving style, described, inter alia, with zero-dimensional characteristics of the speed process;

- Operation of the aftertreatment systems;

- Vehicle load.

The methods of the investigations are a consequence of the use of the measurement results coming from the portable exhaust emission analyzer (PEMS) in the RDE test. This system enables real time measurement of the engine parameters [1,7-9,14].

The exhaust gas analysis was performed using the Semtech DS equipment [18], fitted with the following measurement modules:

- FID (Flame Ionization Detector) for the measurement of the concentration of hydrocarbons;

- $\quad$ NDUV (Non-Dispersive Ultraviolet) analyzer-non-dispersive, utilizing ultraviolet radiation for the measurement of the concentration of nitrogen monoxide and dioxide;

- $\quad$ NIDR (Non-Dispersive Infrared) analyzer-non-dispersive utilizing infrared radiation for the measurement of the concentration of carbon monoxide and carbon dioxide;

- Electrochemical analyzer for the measurement of the concentration of oxygen.

The measurement of the mass flow of the exhaust gas was also realized using the Semtech DS analyzer. For the measurement of the particle emission, a TSI 3090 EPSS ${ }^{\mathrm{TM}}$ (Engine Exhaust Particle Sizer ${ }^{\mathrm{TM}}$ Spectrometer) analyzer was applied [19]. The measurement quantities in the tests under dynamic states were recorded with the resolution of $10 \mathrm{~Hz}$.

The research methodology pertained to the conditions of the vehicle in motion and the states of the vehicle operation, including the exhaust emissions. The recorded results were filtered using the Savitzky-Golay filter of the second order [22] in order to reduce the high frequency noise in the signals.

The beginning and the end of each test run were the premises of Poznan University of Technology (Piotrowo 3). The test route was composed of the urban portion running through the streets of Poznan, the rural portion extending from the city of Poznan, the town of Suchy Las to the S11 expressway and the motorway portion partly running through the S11 expressway and the A2 motorway (Figure 2). The total length of the route was approx. $75 \mathrm{~km}$. 


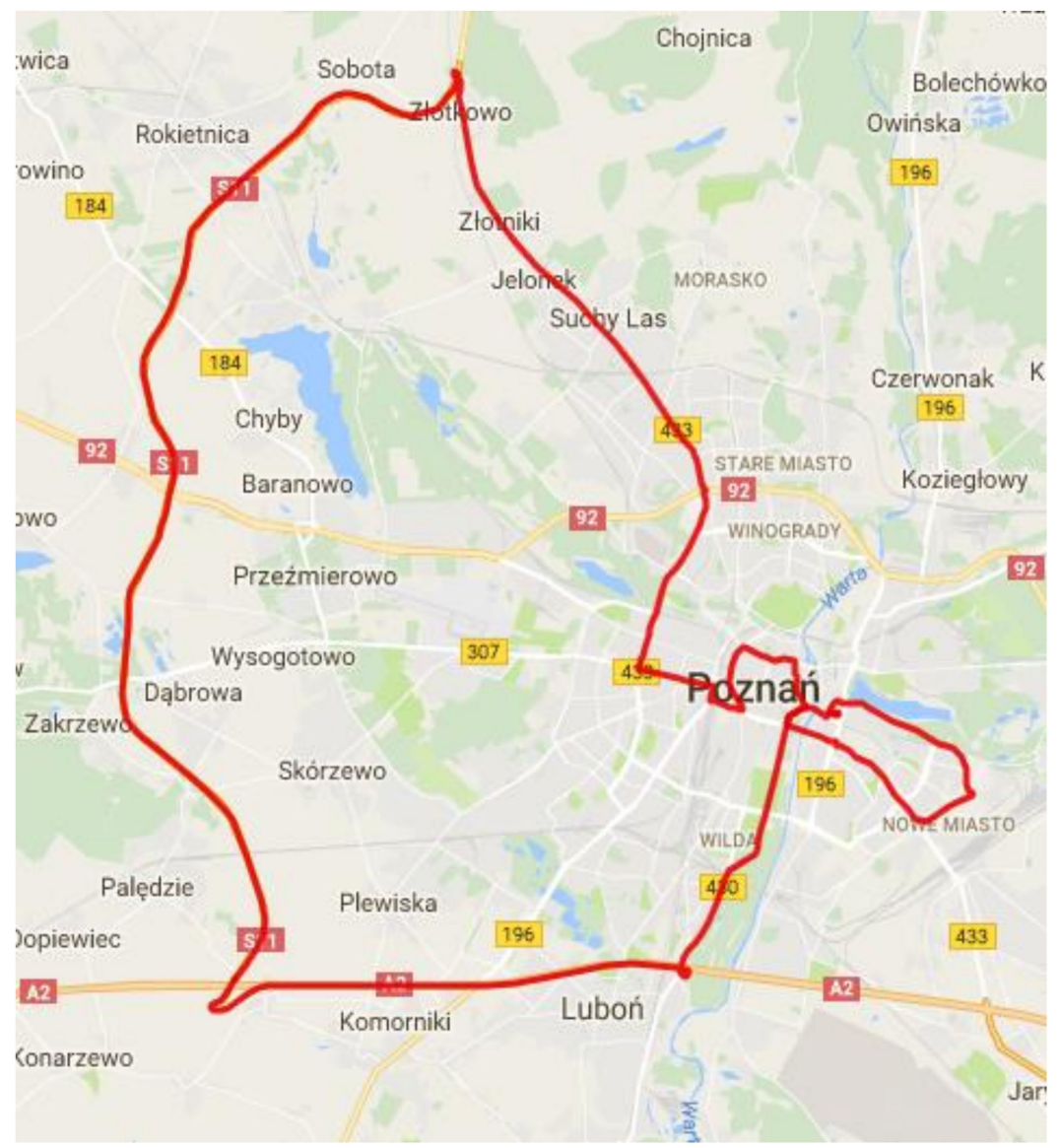

Figure 2. The test route of the RDE test carried out by the authors (based on the GPS data).

\section{Research Methodology}

The research methodology pertained to the vehicle driving conditions, its engine states and exhaust emissions under actual traffic operation.

The research program included the completion of the RDE test. During the tests, the following fundamental quantities were recorded:

- Vehicle speed;

- Fuel flow intensity;

- Concentration of the exhaust components: carbon monoxide, hydrocarbons, nitrogen oxides and carbon dioxide;

- Particle number intensity.

There were many other control values, not directly used in the described investigations.

The investigations of the conditions pertained to the process of vehicle speed. The following were determined for the individual phases of the test and for the entire test:

- $\quad$ Average speed $\left(\mathrm{v}_{\mathrm{AV}}\right)$;

- Average value of the product 11 of speed and acceleration (A).

$$
\mathrm{A}=\mathrm{AV}(\mathrm{v} \cdot \mathrm{a}),
$$

where $\mathrm{AV}$ represents the average value operator.

The average value of the product of speed and acceleration characterizes the dynamic properties of the test $[5,23]$. Therefore, the authors investigated the relations of the average value of speed and the average value of the product of speed and acceleration: $\mathrm{A}-\mathrm{v}_{\mathrm{AV}}$. 
The engine state of thermal stabilization was defined by the engine speed (n) and torque $\left(\mathrm{M}_{\mathrm{e}}\right)$. For the analysis, a relative torque was adopted defined according to the Formula (2)

$$
\mathrm{M}_{\mathrm{er}}(\mathrm{n})=\frac{\mathrm{M}_{\mathrm{e}}(\mathrm{n})}{\mathrm{M}_{\mathrm{eext}}(\mathrm{n})}
$$

where $\mathrm{M}_{\text {eext }}$-torque at full throttle.

According to the adopted methodology, the investigations covered the emissions of carbon monoxide $(\mathrm{CO})$, hydrocarbons $(\mathrm{HC})$, nitrogen oxides $\left(\mathrm{NO}_{\mathrm{x}}\right)$ carbon dioxide $\left(\mathrm{CO}_{2}\right)$ and particle number (PN).

Based on the RDE test results, the applied methodology included the determination of the following:

- Processes of the exhaust emission intensity $\left(\mathrm{E}_{\mathrm{CO}}, \mathrm{E}_{\mathrm{HC}}, \mathrm{E}_{\mathrm{NO}}, \mathrm{E}_{\mathrm{CO} 2}\right)$ and the particle number intensity $\left(\mathrm{E}_{\mathrm{PN}}\right)$;

- Processes of the specific distance exhaust emissions $\left(b_{\mathrm{CO}}, \mathrm{b}_{\mathrm{HC}}, \mathrm{b}_{\mathrm{NO}}, \mathrm{b}_{\mathrm{CO} 2}\right)$ and the specific distance particle number $\left(\mathrm{b}_{\mathrm{PN}}\right)$.

For the individual phases and the entire test, the authors determined the zerodimensional characteristics: average value (AV), standard deviation (D) and extreme values (Min, Max) of the specific distance emission of the individual exhaust components, as well as the specific distance particle number. Based on the calculated zero-dimensional characteristics, the coefficient of variability of the investigated physical quantities was determined

$$
\mathrm{W}=\frac{\mathrm{D}}{\mathrm{AV}}
$$

Based on the zero-dimensional characteristics of the speed process and the exhaust emission processes, a dependence was determined of the average specific distance exhaust emissions/the average specific distance particle number on the average vehicle speed. The dependence of the discrete values of the individual specific distance emission components and the specific distance particle number for the individual portions of the test and for the entire test on the average vehicle speed is expressed with a function (4):

$$
\hat{\mathbf{b}}=\mathbf{F}\left(\mathrm{v}_{\mathrm{AV}}\right)
$$

where $\mathbf{F}$-matrix function, $\hat{\mathbf{b}}$-matrix of the specific distance emission of the individual exhaust components and the specific distance particle number for the individual phases of the test:

$$
\hat{\mathbf{b}}=\left[\mathrm{b}_{\mathrm{ij}}\right]
$$

where $\mathrm{i}=\mathrm{CO}$ for the emission of carbon monoxide, $\mathrm{i}=\mathrm{HC}$ for the emission of hydrocarbons, $\mathrm{i}=\mathrm{NO}_{\mathrm{x}}$ for the emission of nitrogen oxides, $\mathrm{i}=\mathrm{CO}_{2}$ for the emission of carbon dioxide, $\mathrm{i}=\mathrm{PN}$ for the particle number, $\mathrm{j}=\mathrm{RDE}-\mathrm{U}$ for the urban portion of the test, $\mathrm{j}=\mathrm{RDE}-\mathrm{R}$ for the rural portion of the test, $\mathrm{j}=\mathrm{RDE}-\mathrm{H}$ for the motorway portion of the test, $\mathrm{j}=\mathrm{RDE}$ for the entire test.

The discrete relations (4) for the individual exhaust components were approximated with the function relations:

$$
\mathbf{b}=\mathbf{f}\left[\mathrm{v}_{\mathrm{AV}}\right]
$$

where $\mathbf{f}$-vector function, $\mathbf{b}=\left[\mathrm{b}_{\mathrm{i}}\right]$-specific distance emission vector of the individual exhaust components and the particle number for the individual portions of the test and for the entire test.

For the approximation, the authors used a multinomial function. The quality of the approximation was evaluated by obtaining the coefficient of determination of the adaptation of the approximating functions to the discrete values of the specific distance emission of the individual exhaust components and the particle number in the individual portions of the test, as well as the entire test. The characteristics determined in this way are 
commonly applied in the modeling of exhaust emissions from motor vehicles [23-27]. It is generally known that these characteristics correspond to the RDE test conditions.

In order to assess the influence of the model of vehicle in motion on the specific distance exhaust emissions and the particle number, the zero-dimensional characteristics of the specific distance exhaust emissions and the specific distance particle number were determined for the following sets: individual test portions and the entire test. For these sets, the following were determined: the average value, the extreme values, the standard deviation and the coefficient of variability. The authors also determined the relative difference in the exhaust emissions and particle number for the individual portions of the tests and for the entire test:

$$
\delta=\frac{b_{i j}}{b_{R D E}}
$$

where $b_{i j}$-element of matrix of the specific distance exhaust emissions and specific distance particle number for the individual portions of the test, $\mathrm{i}, \mathrm{j}$ - as for Formula (5).

\section{Research Results and Discussion}

Table 3 presents the characteristics of the test run and Figure 3 the process of the vehicle speed.

Table 3. Characteristics of the test run.

\begin{tabular}{lcccc}
\hline \multicolumn{1}{c}{ Test Portion } & Urban & Rural & Motorway & Total \\
\hline $\begin{array}{l}\text { test distance }(\mathrm{km}) \\
\text { test duration }(\mathrm{min})\end{array}$ & 27.71 & 26.59 & 23.74 & 78.03 \\
time of the cold start stage (s) & & & & 104 \\
share of distances of the test portions $(\%)$ & 35.51 & 34.07 & 30.42 & 100 \\
$\begin{array}{l}\text { average speed }(\mathrm{km} / \mathrm{h}) \\
\text { motorway: share of time with the speed }\end{array}$ & 23.58 & 79.43 & 107.64 & 45.10 \\
$\begin{array}{l}\text { in excess of } 145 \mathrm{~km} / \mathrm{h}(\%) \\
\text { motorway: share of time with the speed }\end{array}$ & & 0.00 & \\
$\begin{array}{l}\text { in excess of } 100 \mathrm{~km} / \mathrm{h}(\mathrm{min}) \\
\text { rural: share of stop time }(\%) \\
\text { difference in elevation of the start and }\end{array}$ & & & \\
end points of the test $(\mathrm{m})$ & & & 26.43 \\
\hline
\end{tabular}

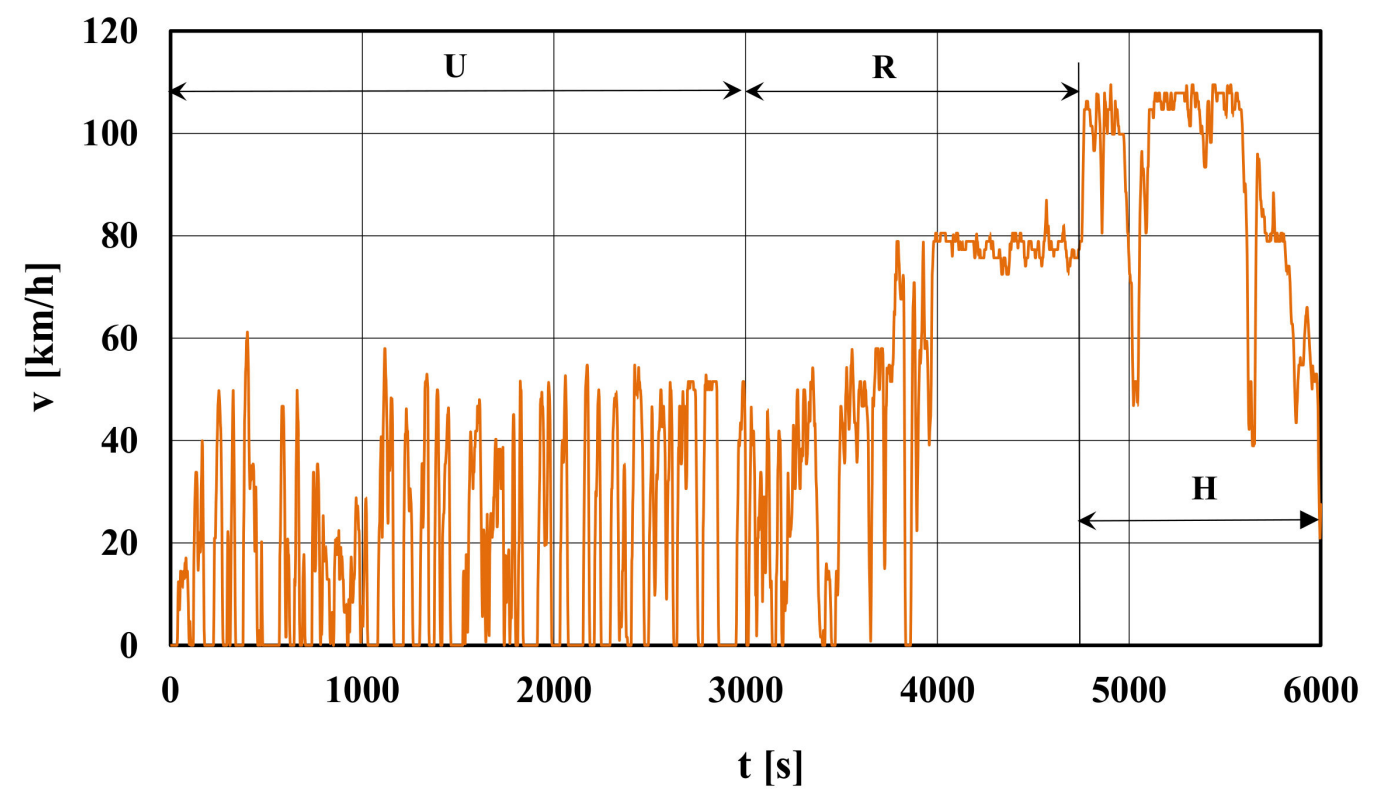

Figure 3. Process of the vehicle speed in the RDE test. 
As shown in Table 2, all formal conditions for the RDE test [1-3,21] were met. Figure 3 shows the phases of the test: $\mathrm{U}$ - urban portion, $\mathrm{R}$-rural portion and $\mathrm{H}$-motorway portion. Figure 4 presents the average speed of the vehicle and the average value of the product of the vehicle speed and its acceleration under the urban, rural and motorway conditions, as well as in the entire test.

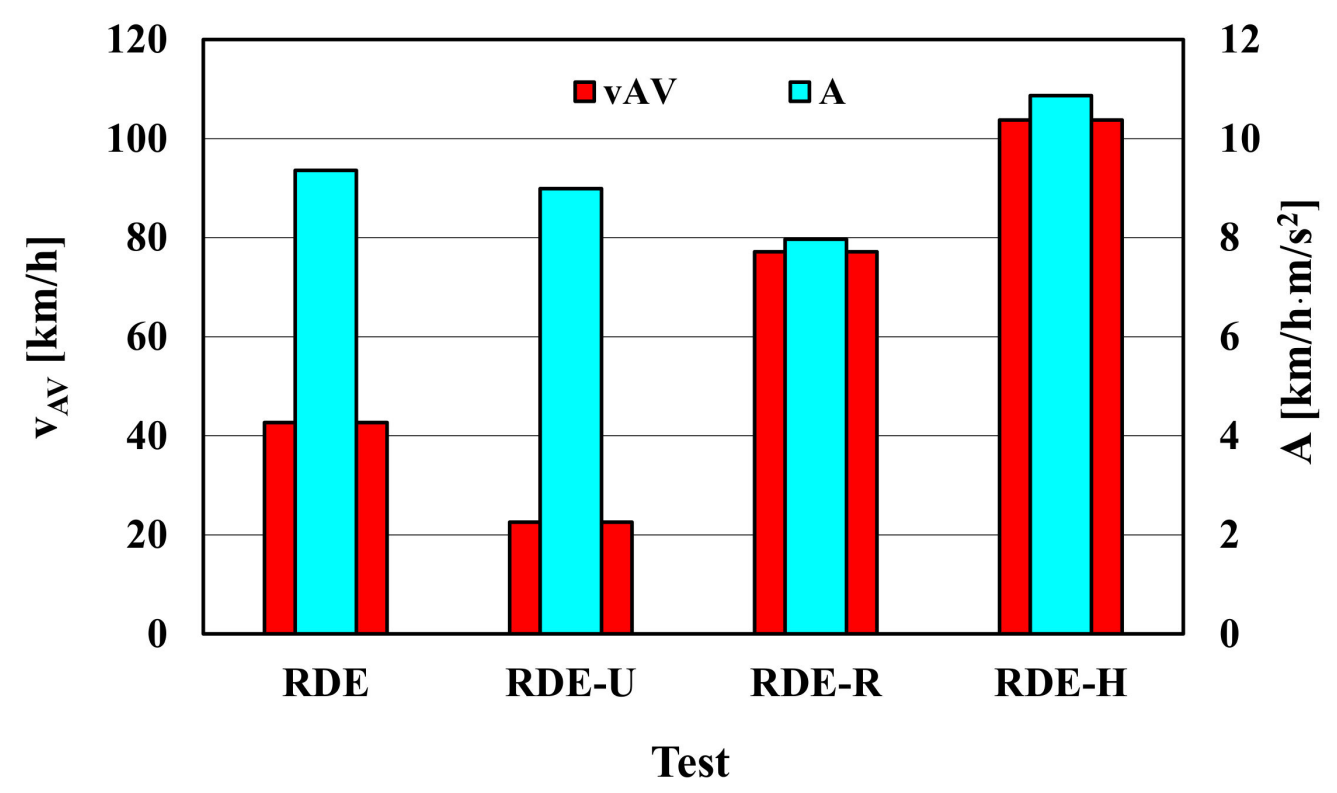

Figure 4. Average speed of the vehicle and the average values of the product of vehicle speed and acceleration under the urban, rural and motorway conditions as well as in the entire test.

The average value of the product of vehicle speed and acceleration characterized the vehicle dynamic loads [5,23]. From Figure 4, it is shown that the greatest dynamic load of the vehicle occurs for the motorway portion of the test. Figure 5 presents the dependence of the product of average speed and the average value of the product of the vehicle speed and its acceleration on the average speed of the vehicle under urban, rural and motorway conditions.

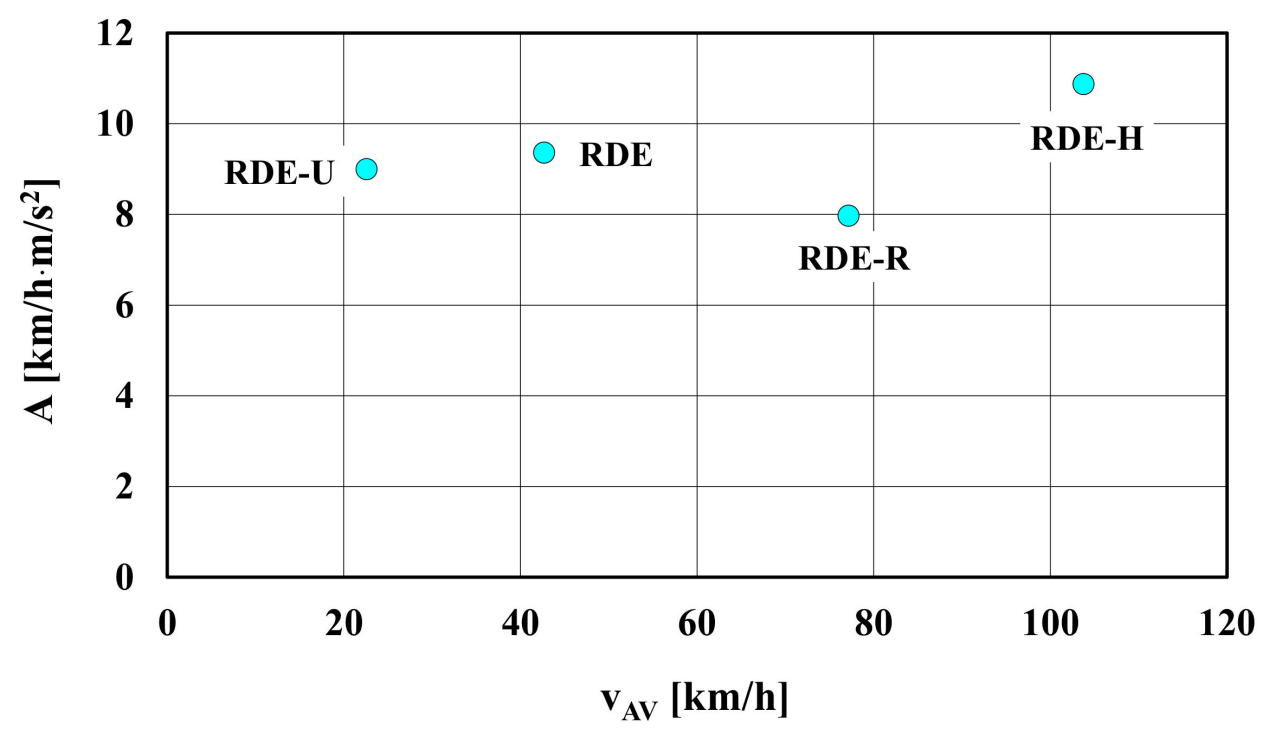

Figure 5. Dependence of the product of average speed and the average value of the product of the vehicle speed and its acceleration on the average speed of the vehicle under urban, rural and motorway conditions. 
We can clearly see the differences in the individual portions of the test in terms of the engine stationary load, mainly dependent on the average speed. The same pertains to the dynamic loads that are dependent on the vehicle acceleration. The engine states during the test have been presented in Figures 6 and 7.

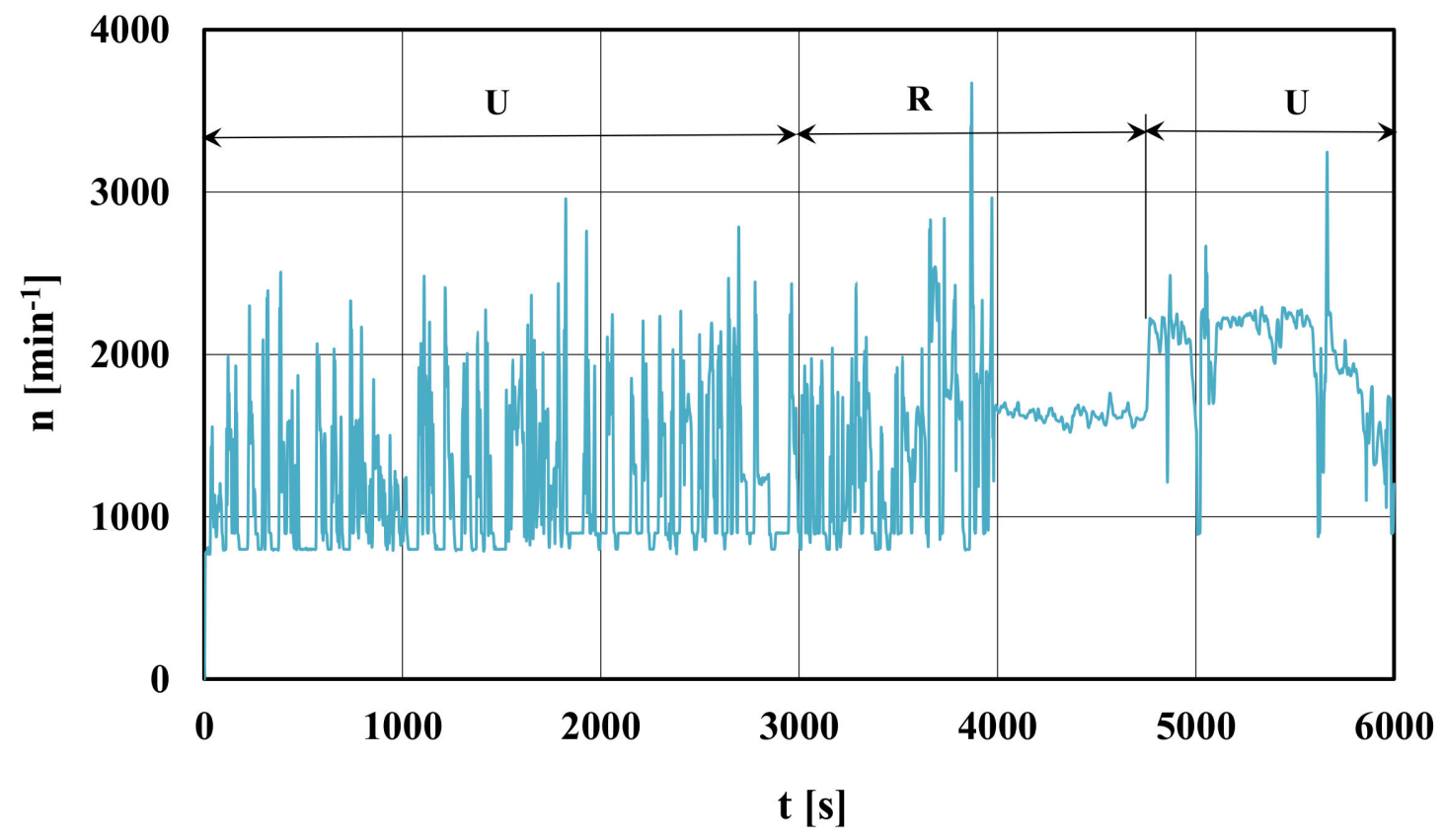

Figure 6. Process of the engine speed in the RDE test.

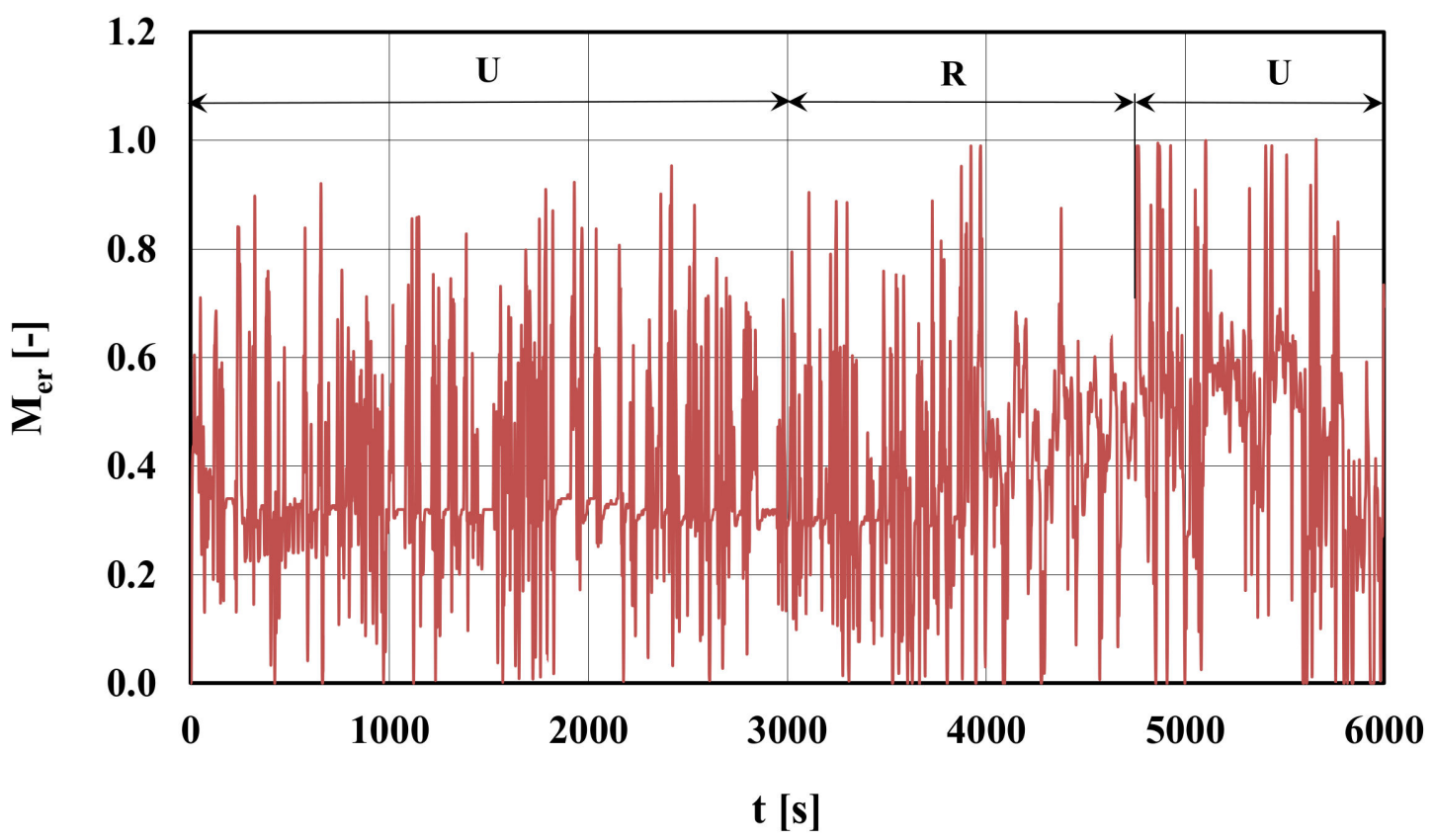

Figure 7. Process of the relative torque in the RDE test.

The variability of the engine speeds and engine states is different in the individual portions of the test. Figure 8 presents the coefficient of variability of the vehicle speed, the engine speed and the relative torque in the individual portions of the test as well as in the entire test. 


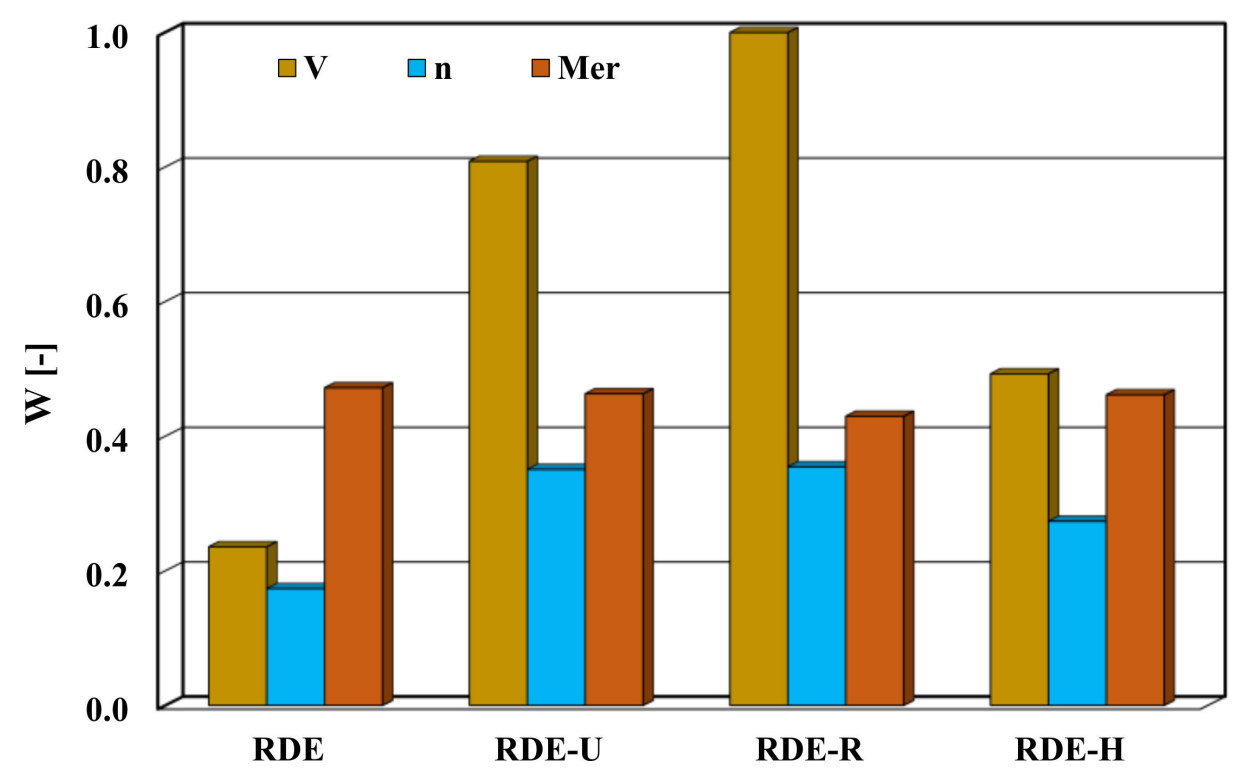

Figure 8. Coefficient of variability of the vehicle speed, the engine speed and the relative torque in the individual portions of the test as well as in the entire test.

Clearly, the most dynamic is the process of vehicle speed in the rural drive, and the least dynamic is the motorway drive. The nature of the engine speed and torque is similar. The difference in the dynamic properties of the speed process in the individual portions of the test is significant: the coefficient of vehicle speed variability in the cities is 1.00 and on the motorway 0.48. This clearly has an impact on the exhaust emissions under dynamic states of the engine operation $[5,23,24,27]$. Figures $9-12$ present the recorded intensity of emission of carbon monoxide, hydrocarbons, nitrogen oxides and carbon dioxide. Figure 13 presents the particle number intensity.

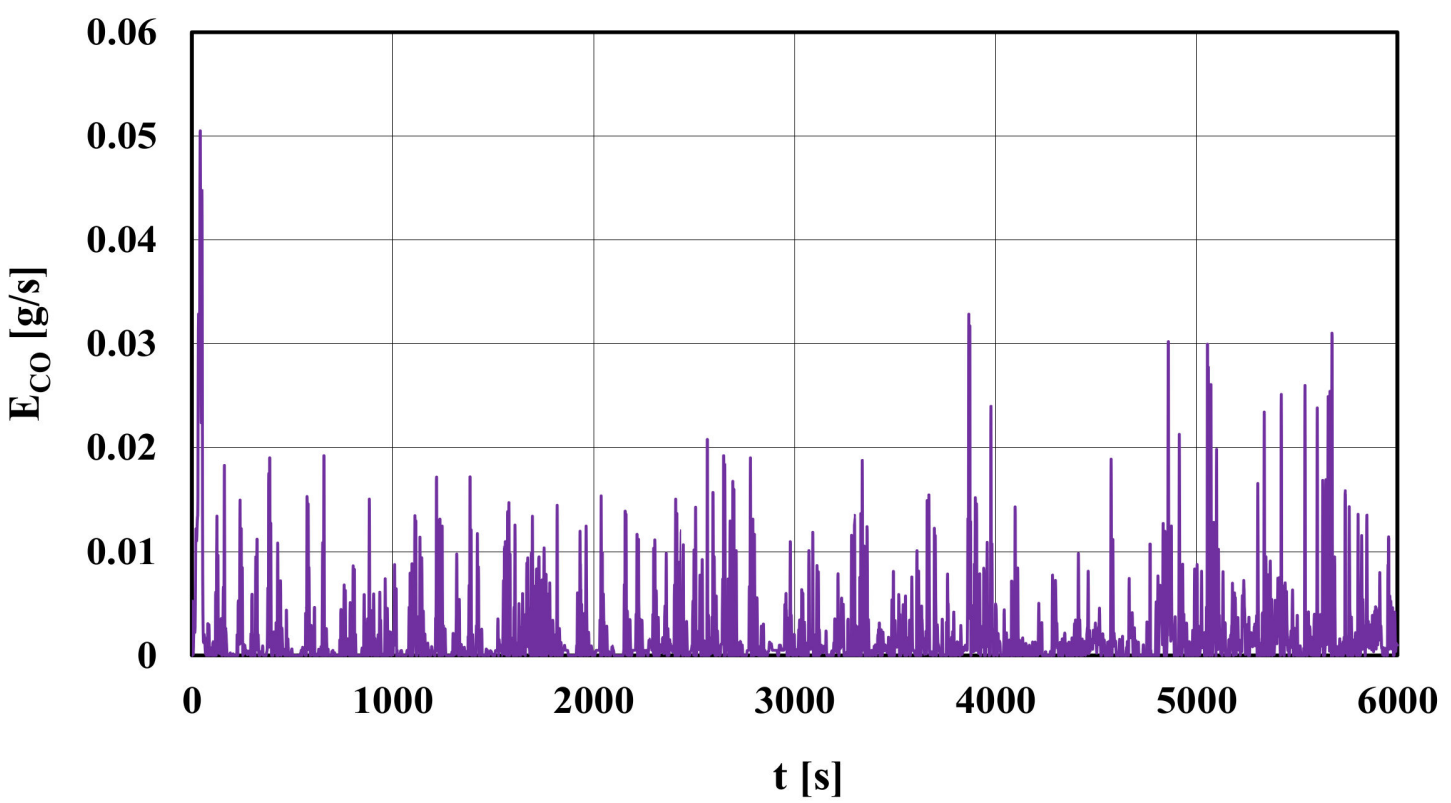

Figure 9. Process of the emission intensity of carbon monoxide in the RDE test. 


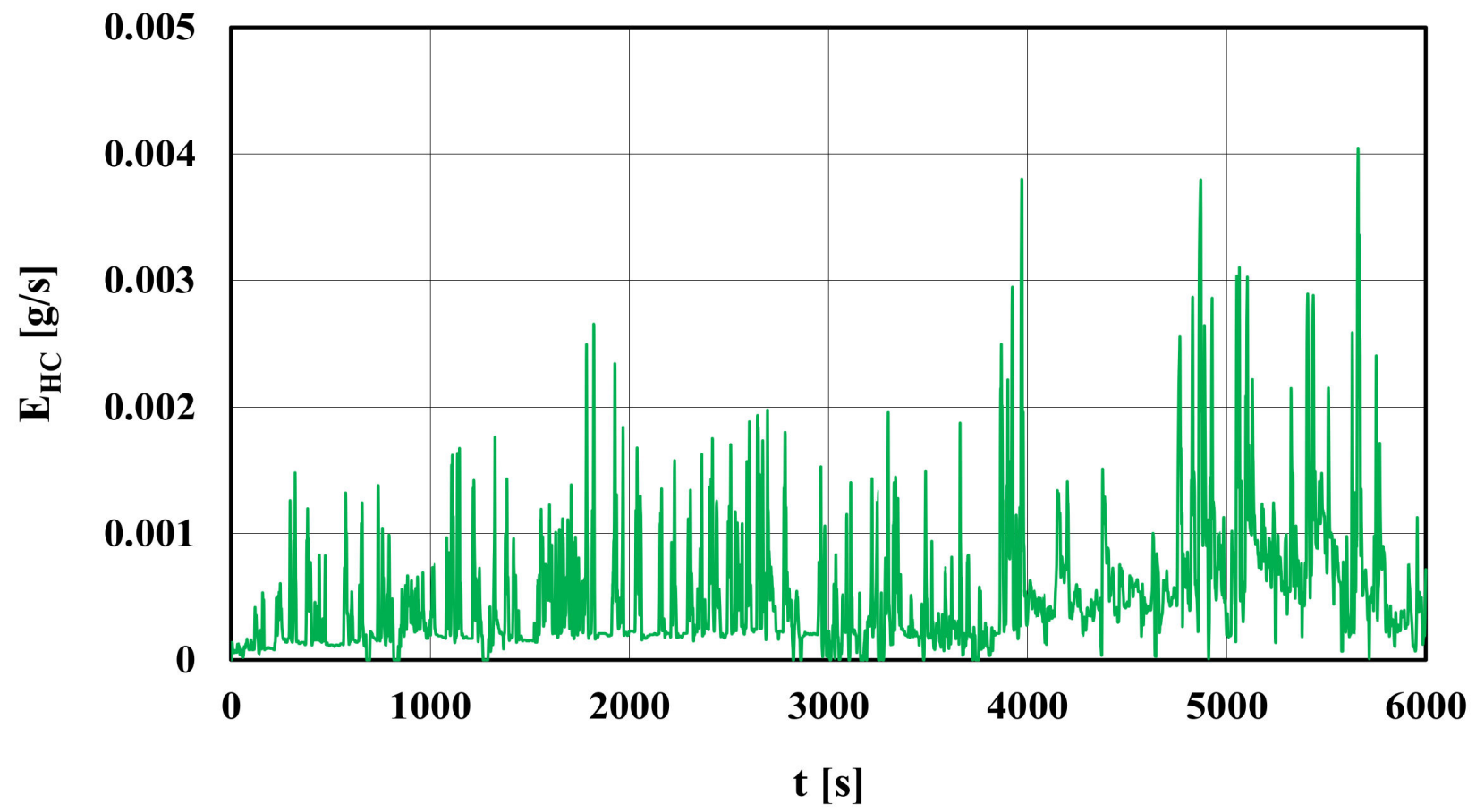

Figure 10. Process of the emission intensity of hydrocarbons in the RDE test.

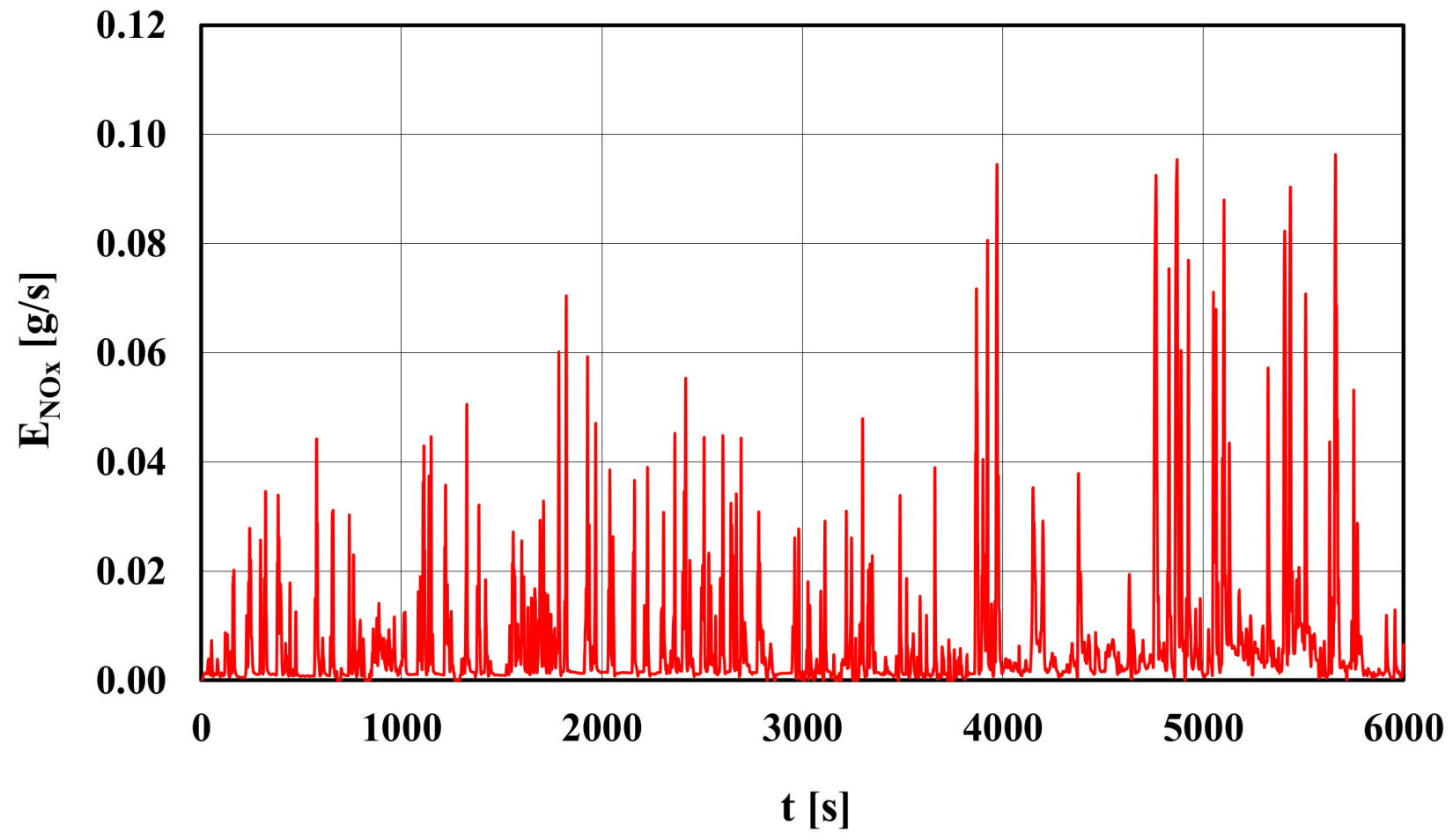

Figure 11. Process of the emission intensity of nitrogen oxides in the RDE test. 


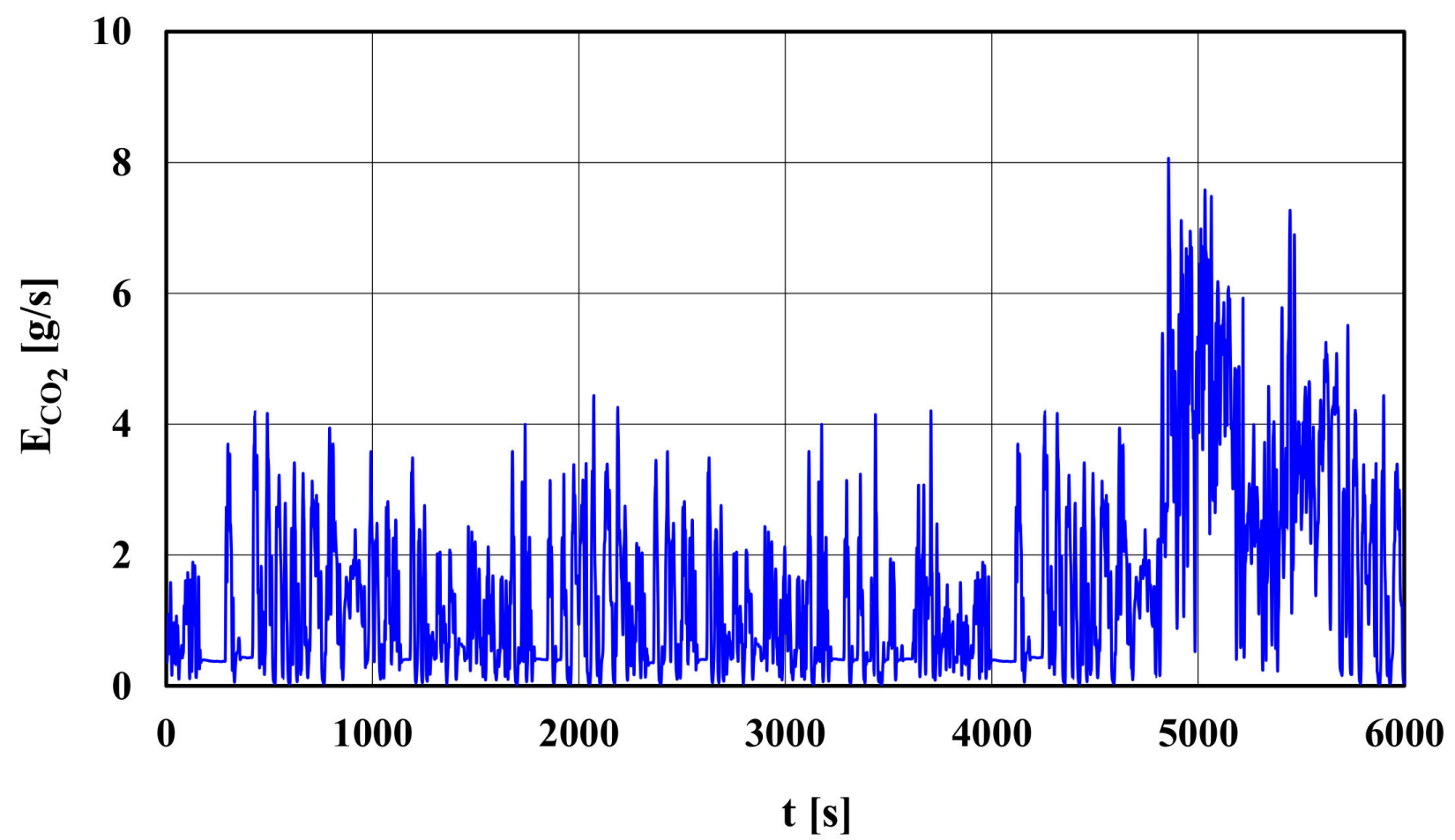

Figure 12. Process of the emission intensity of carbon dioxide in the RDE test.

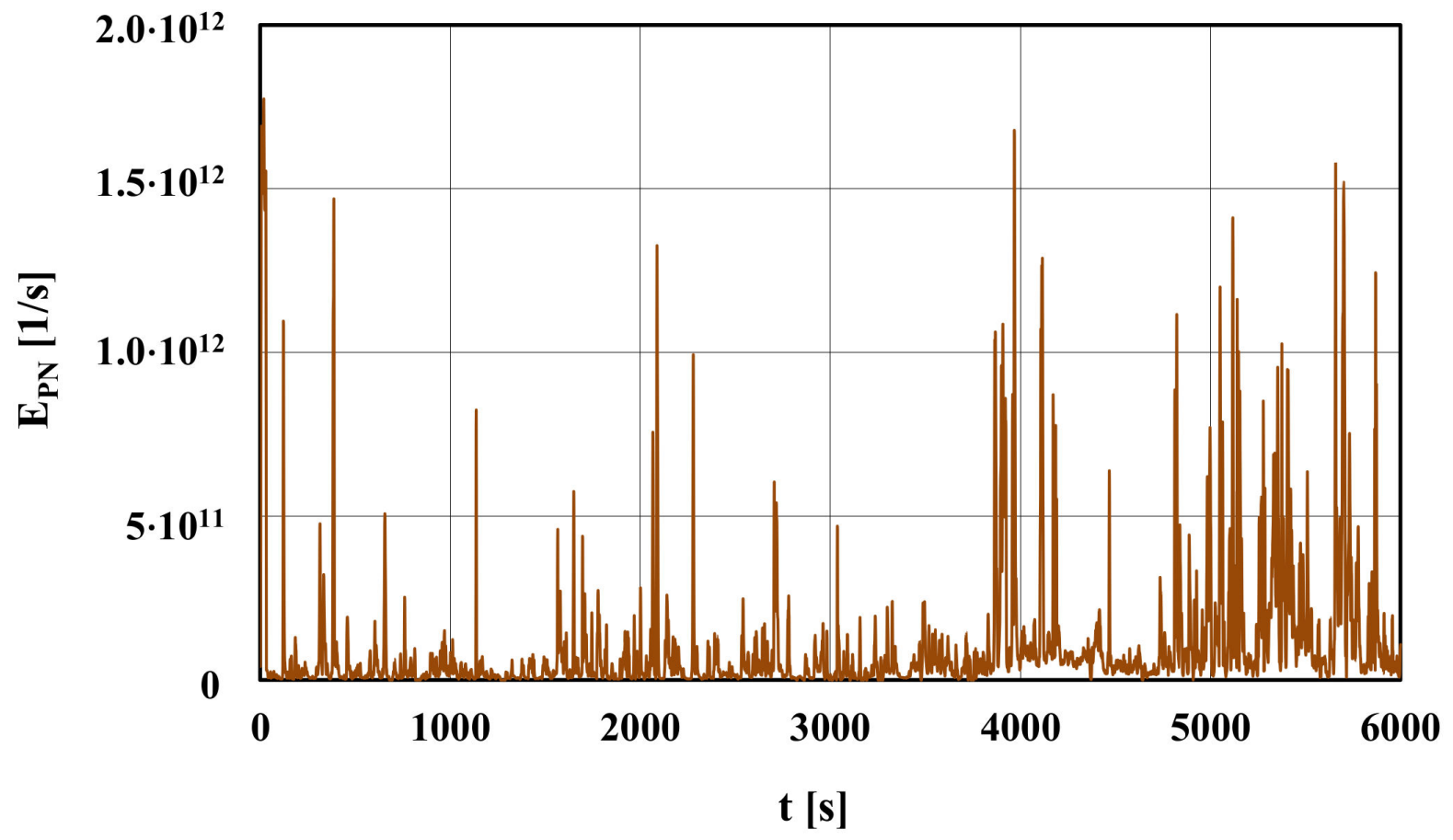

Figure 13. Process of the particle number intensity in the RDE test.

Tables 4 and 5 present the zero-dimensional characteristics of the processes of exhaust emission intensity and the particle number intensity. Figure 14 presents the coefficient of variability of the exhaust emission intensity and the particle number intensity. 
Table 4. Zero-dimensional characteristics of the processes of exhaust emission and the particle number intensity: minimum value, maximum value, average value and standard deviation.

\begin{tabular}{ccccccc}
\hline & Process & $\mathbf{E}_{\mathbf{C O}}$ & $\mathbf{E}_{\mathbf{H C}}$ & $\mathbf{E}_{\mathbf{N O \mathbf { x }}}$ & $\mathbf{E}_{\mathbf{C O} 2}$ & $\mathbf{E}_{\mathbf{P N}}$ \\
\hline Test & & $\mathbf{g} / \mathbf{s}$ & $\mathbf{g} / \mathbf{s}$ & $\mathbf{g} / \mathbf{s}$ & $\mathbf{g} / \mathbf{s}$ & $\mathbf{1 / s}$ \\
\hline \multirow{5}{*}{ RDE } & Min & 0.0000 & 0.0000 & 0.0000 & 0.00 & 0 \\
& Max & 0.0505 & 0.0040 & 0.0963 & 10.57 & $2.95 \cdot 10^{12}$ \\
& AV & 0.0023 & 0.0005 & 0.0067 & 1.51 & $1.09 \cdot 10^{11}$ \\
& D & 0.0042 & 0.0005 & 0.0116 & 1.48 & $1.75 \cdot 10^{11}$ \\
\hline \multirow{5}{*}{ RDE-U } & Min & 0.0000 & 0.0000 & 0.0000 & 0.00 & 0 \\
& Max & 0.0505 & 0.0027 & 0.0702 & 8.45 & $9.67 \cdot 10^{11}$ \\
& AV & 0.0022 & 0.0004 & 0.0055 & 1.07 & $1.18 \cdot 10^{11}$ \\
& D & 0.0043 & 0.0003 & 0.0081 & 1.07 & $1.32 \cdot 10^{11}$ \\
\hline \multirow{5}{*}{ RDE-R } & Min & 0.0000 & 0.0000 & 0.0000 & 0.00 & 0 \\
& Max & 0.0327 & 0.0038 & 0.0945 & 10.26 & $2.95 \cdot 10^{12}$ \\
& AV & 0.0018 & 0.0005 & 0.0053 & 1.36 & $9.69 \cdot 10^{10}$ \\
& D & 0.0032 & 0.0004 & 0.0093 & 1.28 & $2.62 \cdot 10^{11}$ \\
\hline \multirow{5}{*}{ RDE-H } & Min & 0.0000 & 0.0000 & 0.0000 & 0.00 & $1.46 \cdot 10^{9}$ \\
& Max & 0.0310 & 0.0040 & 0.0963 & 10.57 & $7.59 \cdot 10^{11}$ \\
& AV & 0.0031 & 0.0009 & 0.0114 & 2.74 & $1.03 \cdot 10^{11}$ \\
& D & 0.0047 & 0.0007 & 0.0182 & 1.85 & $9.65 \cdot 10^{10}$ \\
\hline
\end{tabular}

Table 5. Coefficient of variability of the exhaust emission intensity and the particle number intensity.

\begin{tabular}{cccccc}
\hline Process & \multirow{2}{*}{$\mathbf{E}_{\mathbf{C O}}$} & $\mathbf{E}_{\mathbf{H C}}$ & $\mathbf{E}_{\mathbf{N O x}}$ & $\mathbf{E}_{\mathbf{C O} 2}$ & $\mathbf{E}_{\mathbf{P N}}$ \\
\cline { 1 - 5 } Test & & & & & \\
\cline { 1 - 1 } RDE & 1.526 & 0.762 & 1.605 & 0.674 & 0.933 \\
RDE-U & 1.815 & 0.971 & 1.741 & 0.984 & 1.600 \\
REDE-R & 1.937 & 0.923 & 1.483 & 1.005 & 1.110 \\
RDE-H & 1.788 & 0.905 & 1.773 & 0.940 & 2.701 \\
\hline
\end{tabular}

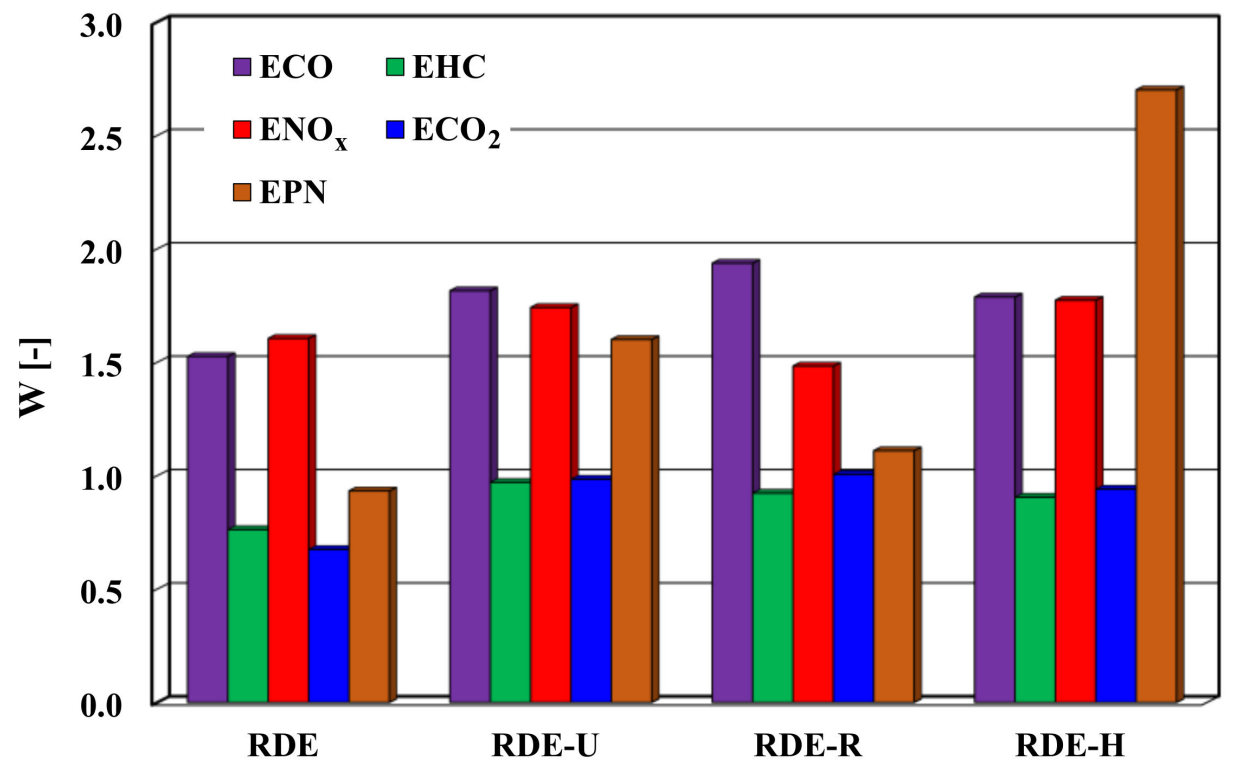

Figure 14. The coefficient of variability of the exhaust emission intensity and the particle number intensity.

In general, the least sensitive to the dynamic conditions is the process of the emission intensity of carbon dioxide and hydrocarbons. On a similar level is the coefficient of variability of carbon monoxide and nitrogen oxides. Characteristic is the high coefficient of 
variability of the process of the particle number intensity in the motorway portion of the test. This is attributed to the significant engine loads, both static and dynamic. Figures 15-18 present the average specific distance emission of carbon monoxide, hydrocarbons, nitrogen oxides and carbon dioxide and Figure 19 presents the average specific distance particle number in the individual portions of the RDE test as well as in the entire test.

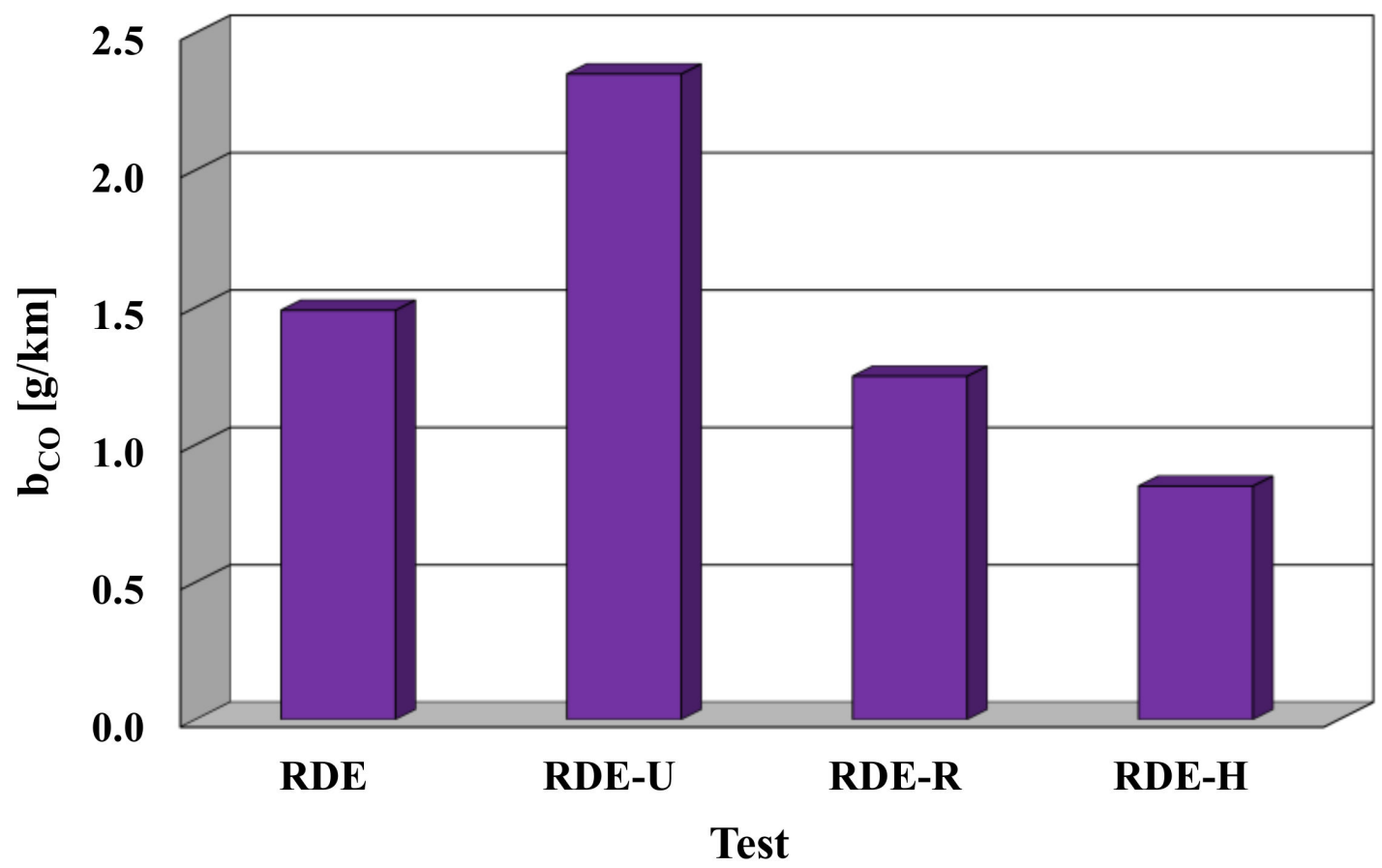

Figure 15. Average specific distance emission of carbon monoxide in the individual portions of the RDE as well as in the entire test.

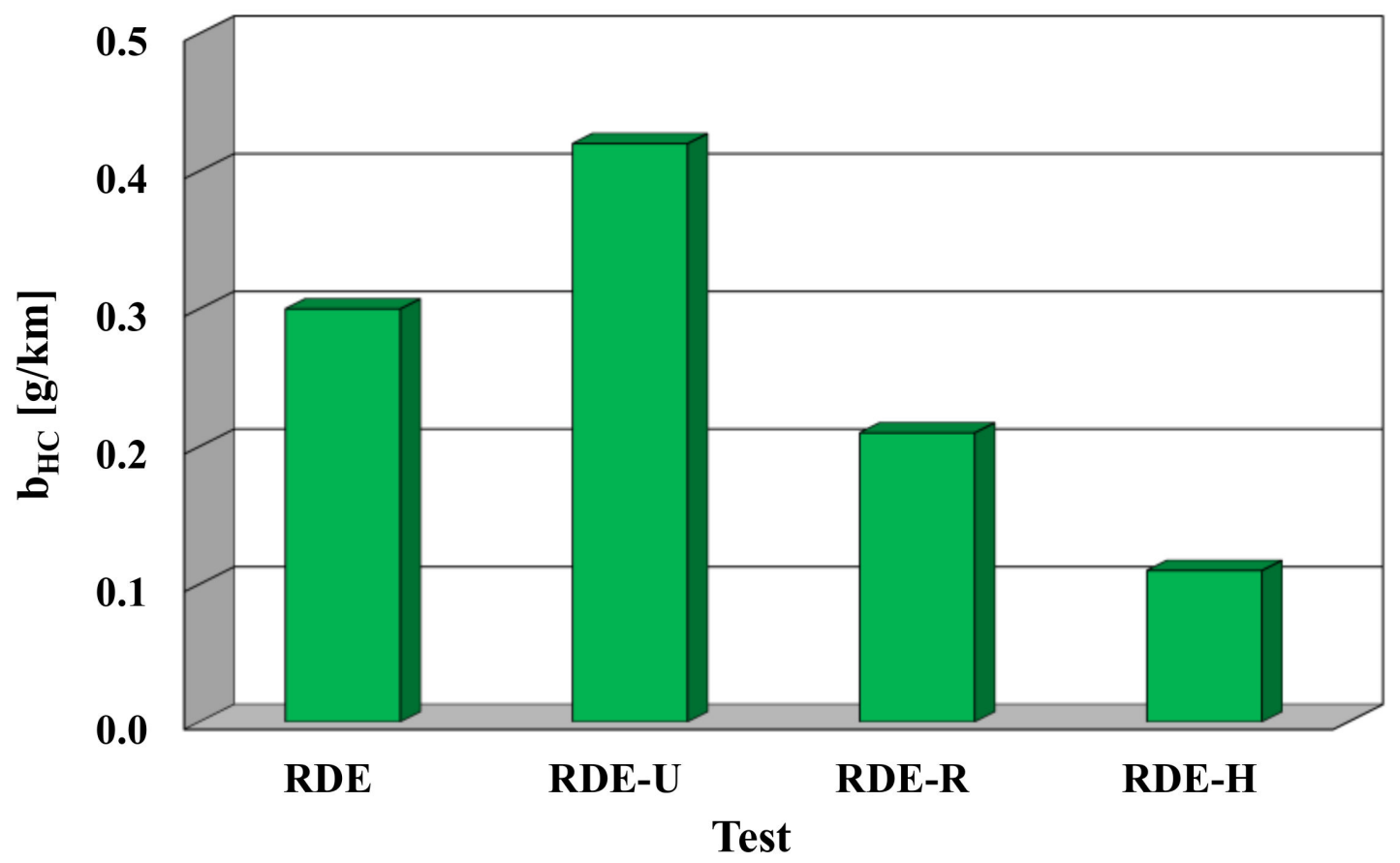

Figure 16. Average specific distance emission of hydrocarbons in the individual portions of the RDE as well as in the entire test. 


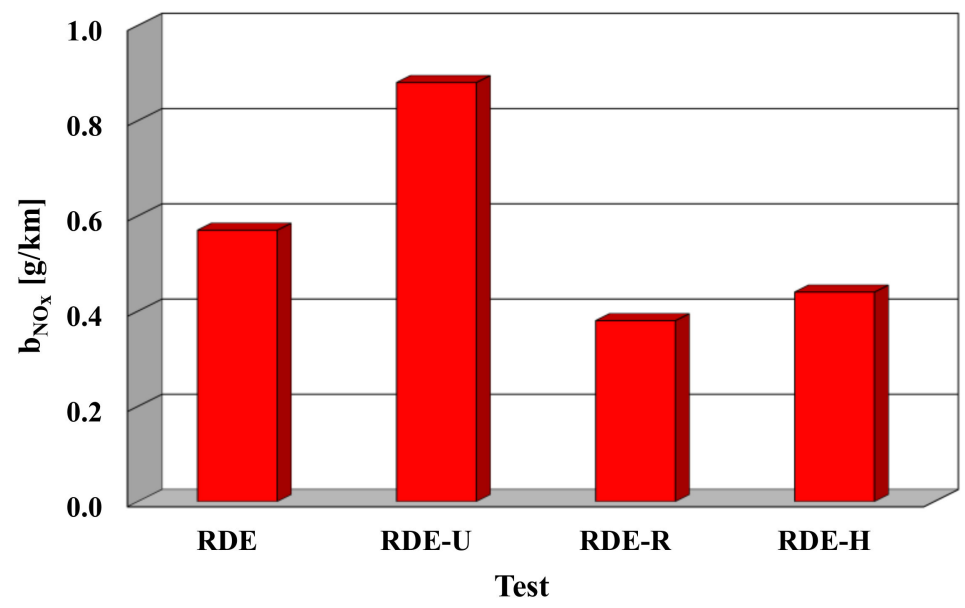

Figure 17. Average specific distance emission of nitrogen oxides in the individual portions of the RDE as well as in the entire test.

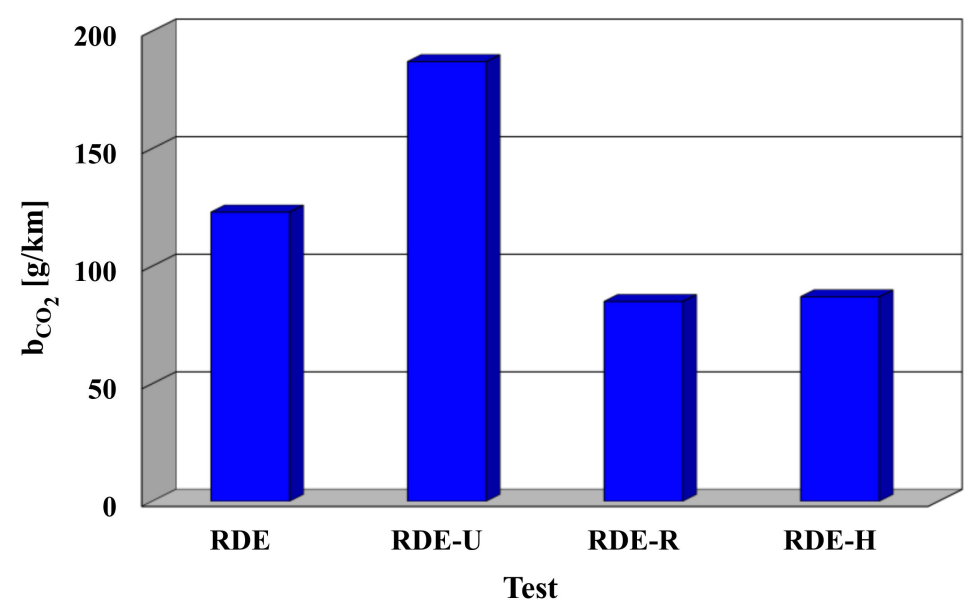

Figure 18. Average specific distance emission of carbon dioxide in the individual portions of the RDE as well as in the entire test.

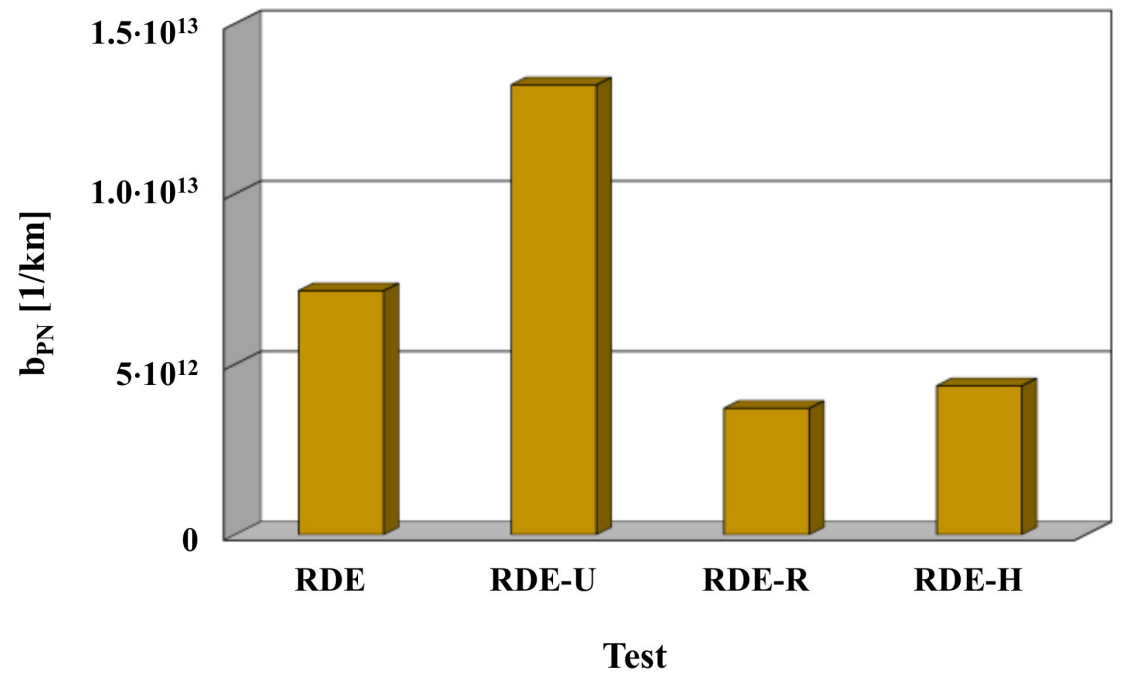

Figure 19. Average specific distance particle number in the individual portions of the RDE as well as in the entire test.

The average specific distance exhaust emissions and the average specific distance particle number vary in the individual portions of the test and in the entire RDE test. It is a 
regularity that the greatest value of the average specific distance exhaust emissions and the average specific distance particle number occurs in the urban portion of the test. This primarily results from the lowest overall efficiency of the engine under non-steady states of operation, due to the non-steady vehicle speed process. As a consequence, under such driving conditions, the fuel consumption is the highest. In the case of carbon monoxide and hydrocarbons, the average specific distance emission is the lowest for the motorway portion of the test, in the case of carbon dioxide, the average specific distance emission in the rural portion and the motorway portion are on a similar level. It is also conspicuous that, in the case of nitrogen oxides, the average specific distance emission on the motorway is higher, compared to the rural portion of the test. This primarily results from the fact that the high emission of nitrogen oxides is governed by the non-steady states of the engine operation and the engine loads. A similar situation is observed for the particle number. In order to provide a more detailed analysis of the average specific distance exhaust emissions in the RDE test, the authors attempted to investigate the dependence of the average specific distance exhaust emissions and the average specific distance particle number in the individual portions of the test and in the entire RDE test on the average vehicle speed and the sensitivity of the said exhaust emissions to the vehicle driving conditions in the urban, rural and motorway portions of the tests against the averaged values of the entire RDE test. Figures 20-24 present the dependence of the average specific distance exhaust emissions and the average specific distance particle number in the individual portions of the test and in the entire RDE test on the average vehicle speed. The sets of points were approximated with a square function.

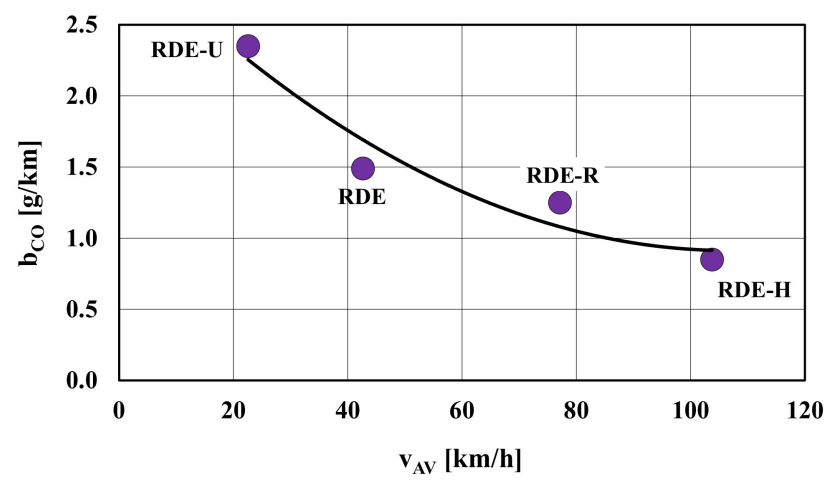

Figure 20. Average specific distance emission of carbon monoxide in the individual portions of the RDE as well as in the entire test, depending on the average vehicle speed.

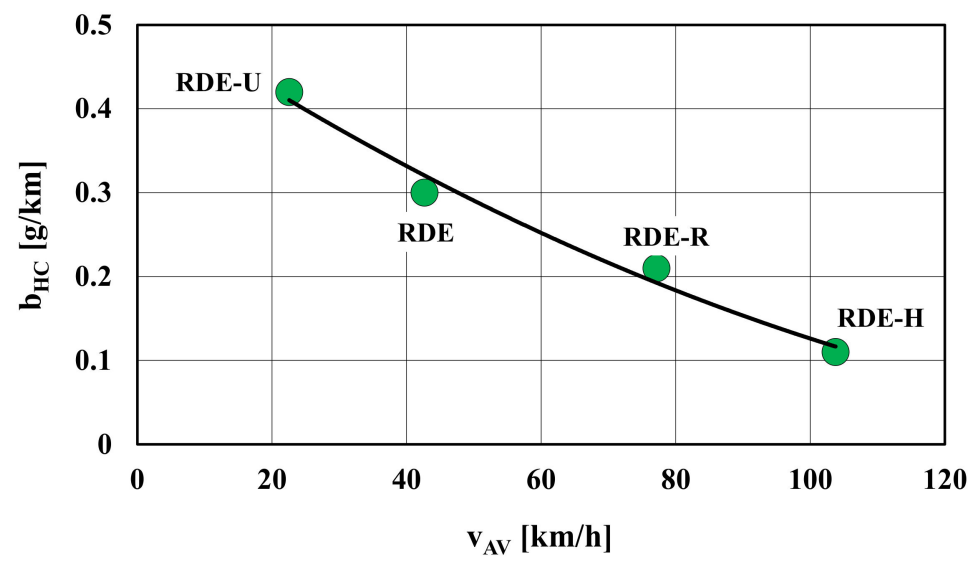

Figure 21. Average specific distance emission of hydrocarbons in the individual portions of the RDE as well as in the entire test, depending on the average vehicle speed. 


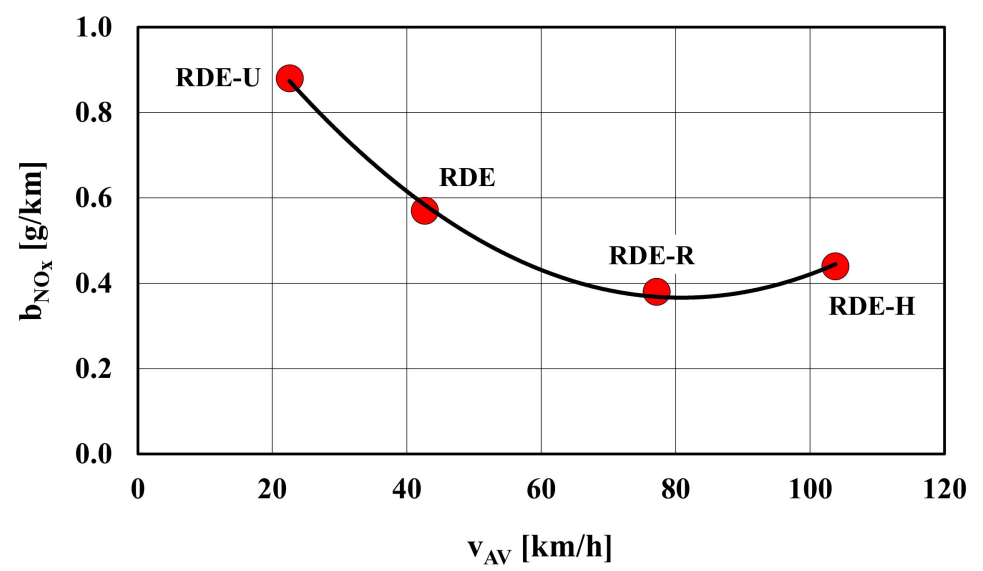

Figure 22. Average specific distance emission of nitrogen oxides in the individual portions of the $\mathrm{RDE}$ as well as in the entire test depending on the average vehicle speed.

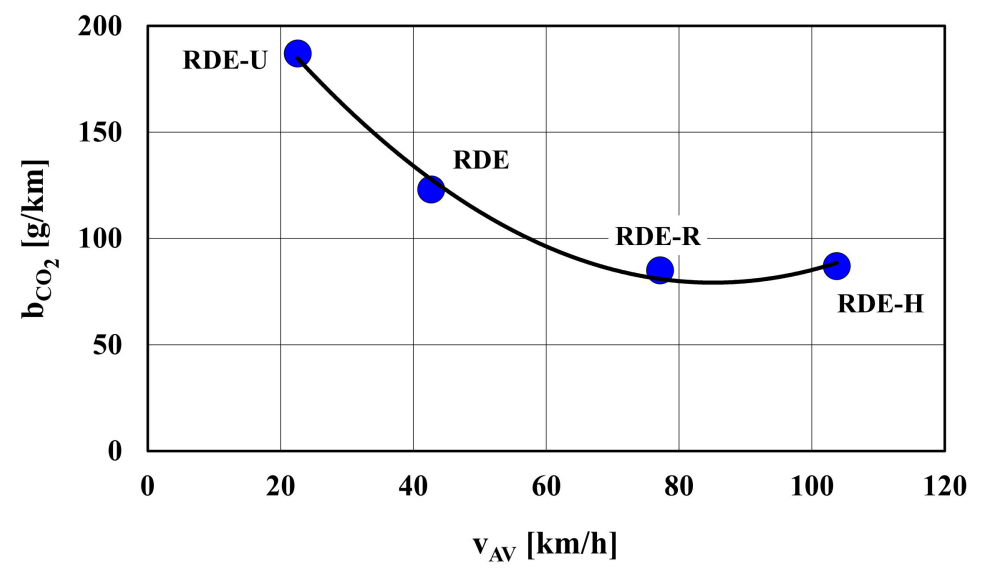

Figure 23. Average specific distance emission of carbon dioxide in the individual portions of the RDE as well as in the entire test depending on the average vehicle speed.

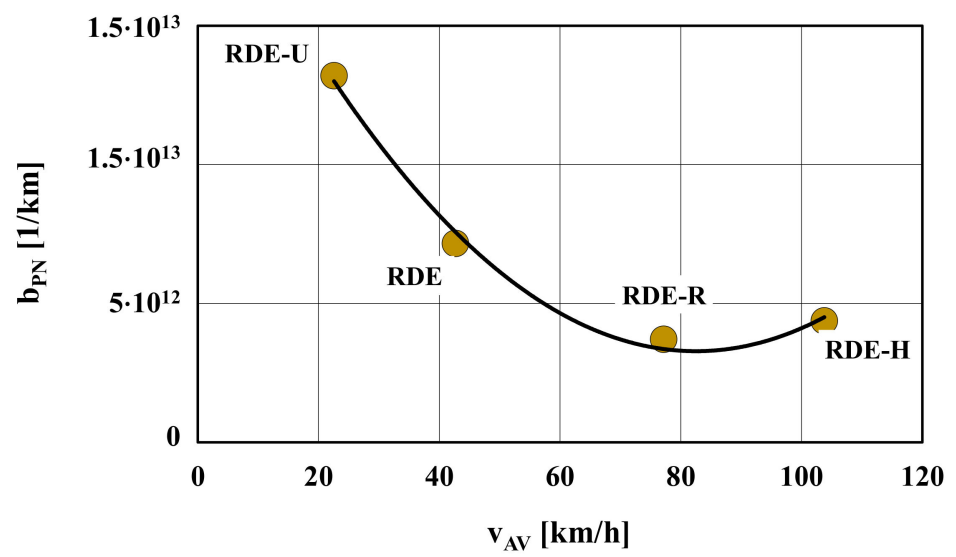

Figure 24. Average specific distance particle number in the individual portions of the RDE as well as in the entire test depending on the average vehicle speed.

The characteristics of the exhaust emissions shown in Figures 20-24 are compliant with the characteristics determined in multiple tests of varied average vehicle speeds. Such characteristics are used in the modeling of the exhaust emissions from motor vehicles [5,23-25,27], e.g., in emission inventory [25], in INFRAS AG [27] and COPERT [24]. For the characteristics presented in Figures 20-24, it is conspicuous that they correspond to the traffic conditions of the RDE test, a test recognized in the homologation procedures 
as representative in terms of actual traffic conditions of passenger vehicles and light-duty trucks. The presented method of determination of the characteristics of exhaust emissions from motor vehicles is also unique for the fact that it is possible to determine these characteristics based on a single test realization, similarly to the Monte Carlo method used for the determination of the characteristics of exhaust emissions from motor vehicles [7].

The assessment of the adequacy of the characteristics of the exhaust emissions can be made by determining the coefficient of determination of the identified models (Figure 25).

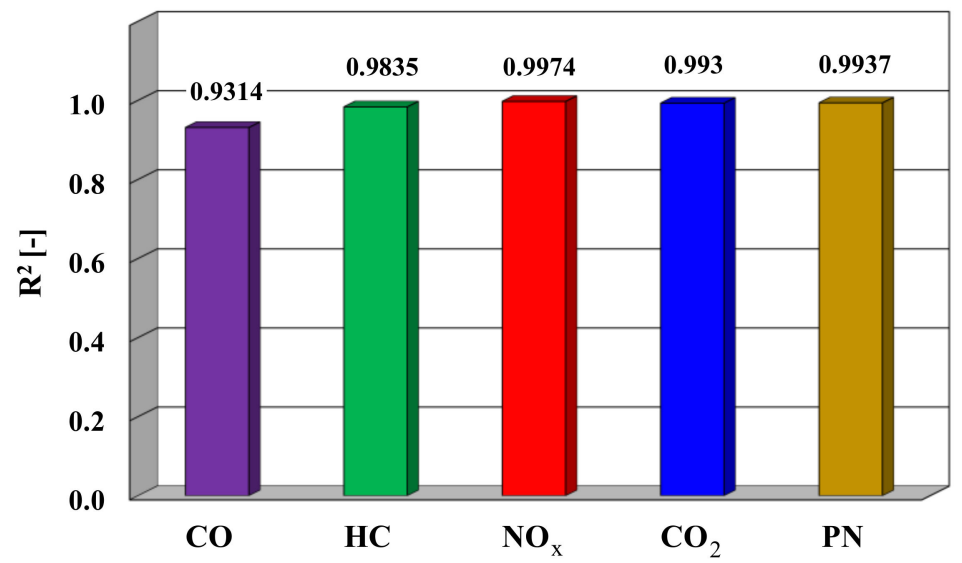

Figure 25. Coefficient of determination of the identified models of characteristics of the exhaust emissions.

The coefficient of determination of the identified models of characteristics of the exhaust emissions has very high values for the individual exhaust components. The lowest value occurs for the specific distance emission of carbon monoxide, but still, the value greater than 0.93 is deemed very high. For the hydrocarbons, this value is greater than 0.98 and, in the outstanding cases, it is greater than 0.99 . The authors also investigated the sensitivity of the level of the exhaust emissions and the particle number to the vehicle driving conditions: urban-rural and motorway-against the averaged conditions in the entire test. Figure 26 presents the relative difference in the specific distance exhaust emissions and the specific distance particle number for the individual portions of the test and for the entire test.

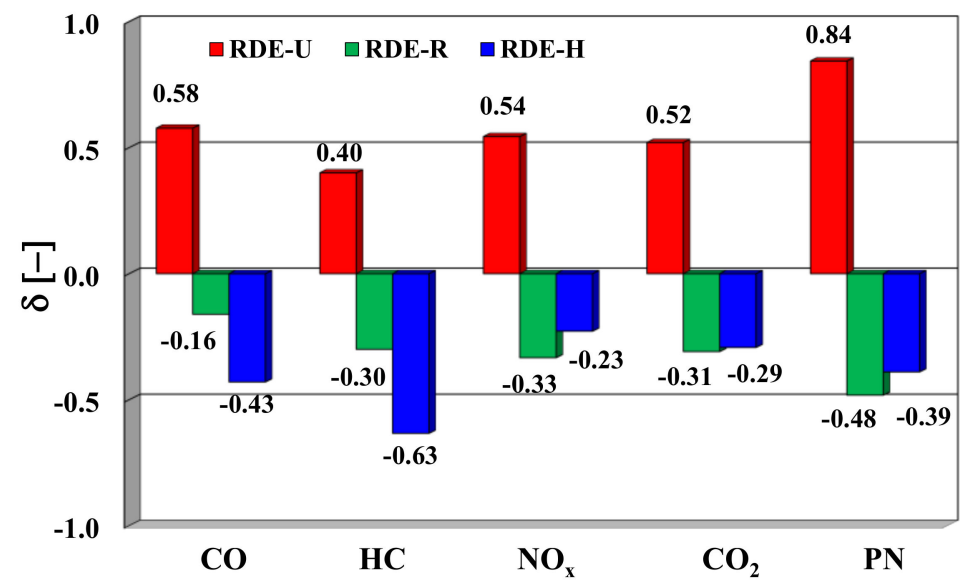

Figure 26. Relative difference in the specific distance exhaust emissions and the specific distance particle number for the individual portions of the test and for the entire RDE test.

The sensitivity of the exhaust emission level and the level of the particle number to the traffic conditions varies for individual exhaust components and traffic conditions.

The absolute value of the sensitivity of the specific exhaust emissions and the specific emission of particulate matter to the conditions determined by the vehicle driving is 
characterized by the tendency towards an increase in these emissions in the individual portions of the test against the entire test. In general, out of all cases, the city traffic favors increased exhaust emissions of particulate matter (prevailingly), carbon monoxide, hydrocarbons and carbon dioxide. The lowest increase occurs for the nitrogen oxides. Under the conditions of rural driving, the highest sensitivity to this portion of the test is for the specific distance particle number and the lowest for the carbon monoxide. Under the conditions of motorway driving the highest sensitivity to this portion of the tests is for the specific distance emission of hydrocarbons and the lowest for nitrogen oxides. In general, the highest sensitivity to the driving conditions is for the particle number (the average value of the relative specific distance particle number for the individual portions of the test and for the entire test is 0.571 ) and the lowest, for the emission of nitrogen oxides and carbon dioxide (the average value of the relative specific distance particle number for the individual portions of the test and for the entire test is 0.368 and 0.374 , respectively). In general, the highest sensitivity of the emissions to the driving conditions is for the urban portion of the test (the average value of the absolute value for all exhaust components is 2.885) and the lowest for the rural portion of the test (the average value of the absolute value of emission sensitivity for all exhaust components is 1.585).

\section{Conclusions}

The investigations of the exhaust emissions from a combustion engine under the conditions of actual operation allow for the validation of the results of the repeatable homologation tests on chassis dynamometers. For tests performed under actual traffic conditions, a certain indeterminacy of the vehicle speed process is conspicuous and, hence, a certain indeterminacy of the engine operating conditions, described in a steady engine thermal state with the processes of engine speed and torque. This indeterminacy allows for treating the recorded engine states in the RDE test as a realization of stochastic processes. As a consequence, the processes of exhaust emissions can also be treated as stochastic in the RDE test. Knowledge acquired in random conditions allows for an assessment of the sensitivity of the exhaust emissions to the variable engine operating states. As a result of the performed investigations, the authors observed a significant diversification of the zerodimensional characteristics of the processes of: vehicle speed, engine speed and torque and, as a consequence, the zero-dimensional characteristics of the processes of exhaust emissions. The strongest dynamic properties occur for the urban traffic conditions. This results in the highest exhaust emissions. The greatest engine load occurs for the motorway traffic conditions. These conditions favor the high emission of nitrogen oxides and particulate matter. Following the analysis of the exhaust emissions, the authors were able to determine the unique characteristics of dependence of the average specific distance exhaust emissions and the average specific distance particle number in the individual portions of the test and in the entire RDE test on the average vehicle speed. These characteristics correspond to the RDE test operating conditions, allowing for a certain indeterminacy of these conditions, which makes these characteristics attributable to the actual operating conditions of a vehicle. The characteristics of exhaust emissions determined under actual operating conditions may be practically used in the simulation research of exhaust emissions under varied real vehicle operating conditions. Owing to the determination of the exhaust emission intensity from the vehicles and the application of models of pollutant propagation, it is possible to obtain a distribution of the concentrations of individual exhaust components in the vicinity of the road. The results of such investigations can be used to assess the transport-related environmental perils under the analyzed traffic conditions.

The authors also investigated the sensitivity of the specific distance exhaust emissions and the specific distance particle number to the vehicle driving style. This sensitivity varies for individual exhaust components and traffic conditions. It was observed that the greatest sensitivity absolute value of the emissions to the traffic conditions occurs for the particle number, and the lowest for nitrogen oxides and carbon dioxide. In terms of the traffic conditions, the greatest sensitivity absolute value of the emissions occurs for the 
urban cycle and the lowest for the motorway cycle. The development of the proposed research methodology may consist in investigating the probabilistic characteristics of quantities describing the exhaust emissions following multiple RDE tests performed on the same vehicle.

A more advanced analysis is also possible for the dependence of the average specific distance exhaust emissions/average specific distance particle number in the individual portions of the test and in the entire test not only on the average speed, but also on the average value of the product of vehicle speed and acceleration characterizing the engine loads under dynamic conditions. This type of analysis in a three-dimensional space requires in-depth research and the selection of a specifications metric [26] that may be deemed as efficient zero-dimensional characteristics, allowing for the obtainment of the research results.

Author Contributions: Conceptualization, Z.C. and J.M.; methodology, Z.C.; software, J.P.; validation, M.A.-Z., J.P. and J.M.; formal analysis, Z.C.; investigation, J.P.; resources, J.M.; writing—original draft preparation, Z.C.; writing—review and editing, J.P.; visualization, J.P.; supervision, J.M.; project administration, M.A.-Z. All authors have read and agreed to the published version of the manuscript.

Funding: This research received no external funding.

Institutional Review Board Statement: Not applicable.

Informed Consent Statement: Not applicable.

Conflicts of Interest: The authors declare no conflict of interest.

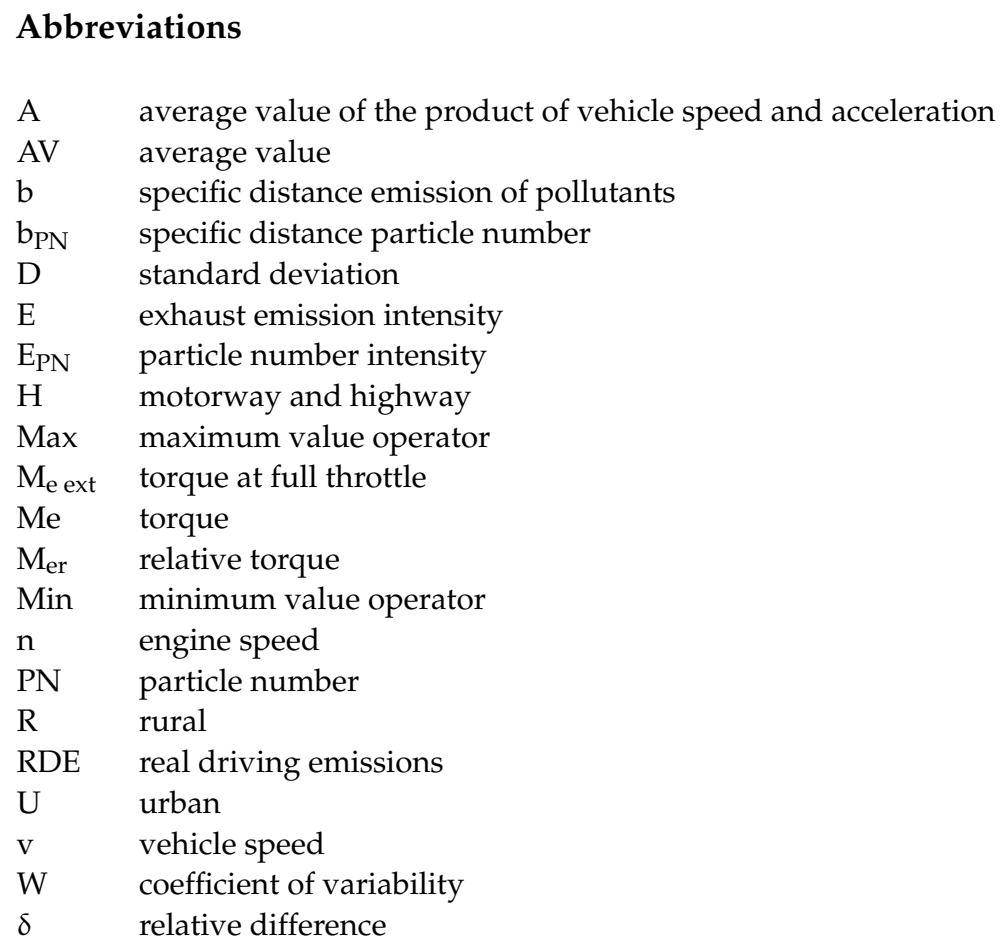

\section{References}

1. Commission Regulation (EU) 2016/427 of 10 March 2016 Amending Regulation (EC) No. 692/2008 as Regards Emissions from Light Passenger and Commercial Vehicles (Euro 6), Verifying Real Driving Emissions. Off. J. Eur. Union 2016, L 82. Available online: http:/ / data.europa.eu/eli/reg/2016/427/oj (accessed on 10 January 2021).

2. Commission Regulation (EU) 2016/646 of 20 April 2016 Amending Regulation (EC) No. 692/2008 as Regards Emissions from Light Passenger and Commercial Vehicles (Euro 6), Verifying Real Driving Emissions. Off. J. Eur. Union 2016, L 109. Available online: http:/ / data.europa.eu/eli/reg/2016/646/oj (accessed on 10 January 2021). 
3. European Commission (2017) Regulation (EC) 2017/1151 of 1 June 2017 Supplementing Regulation (EC) No $715 / 2007$ of the European Parliament and of the Council on Type-Approval of Motor Vehicles with Respect to Emissions from Light Passenger and Commercial Vehicles (Euro 5 and Euro 6) and on Access to Vehicle Repair and Maintenance Information, Amending Directive 2007/46/EC of the European Parliament and of the Council, Commission Regulation (EC) No 692/2008 and Commission Regulation (EU) No 1230/2012 and Repealing Commission Regulation (EC) No 692/2008. Off. J. Eur. Union 2017, L 175, 1-643. Available online: http:/ / data.europa.eu/eli/reg/2017/1151/oj (accessed on 10 January 2021).

4. Worldwide Emission Standards. Passenger Cars and Light Duty Vehicles; Innovation for the Real World; Delphi: London, UK, 2020-2021.

5. Chłopek, Z.; Biedrzycki, J.; Lasocki, J.; Wójcik, P.; Samson-Brek, I. Modelling of motor vehicle operation for the evaluation of pollutant emission and fuel consumption. Combust. Engines 2017, 171, 156-163. [CrossRef]

6. Chłopek, Z.; Biedrzycki, J.; Lasocki, J.; Wójcik, P. Assessment of the impact of dynamic states of an internal combustion engine on its operational properties. Eksploat. I Niezawodn. Maint. Reliab. 2015, 17, 35-41. [CrossRef]

7. Chłopek, Z.; Laskowski, P. Pollutant emission characteristics determined using the Monte Carlo Method. Eksploat. I Niezawodn. Maint. Reliab. 2009, 2, 42-51.

8. Chłopek, Z. Synthesis of driving cycles in accordance with the criterion of similarity of frequency characteristics. Eksploat. I Niezawodn. Maint. Reliab. 2016, 18, 572-577. [CrossRef]

9. Metropolis, N.; Ulam, S. The Monte Carlo Method. J. Am. Stat. Assoc. 1949, 247, 335-341. [CrossRef]

10. Andrych-Zalewska, M.; Chłopek, Z.; Merkisz, J.; Pielecha, J. Evaluation of the test drive cycle conditions impact on exhaust emissions from an internal combustion engine. Combust. Engines 2018, 175, 3-9. [CrossRef]

11. Concawe. A Comparison of Real Driving Emissions from Euro 6 Diesel Passenger Cars with Zero Emission Vehicles and Their Impact on Urban Air Quality Compliance. Urban Air Quality Study: Extension I; Report 8/18; Concawe: Brussels, Belgium, 2018.

12. Czerwinski, J.; Zimmerli, Y.; Hüssy, A.; Engelmann, D.; Bonsack, P.; Remmele, E.; Huber, G. Testing and evaluating real driving emissions with PEMS. Combust. Engines 2018, 173, 17-25. [CrossRef]

13. International Transport Forum. Real-Word Vehicle Emissions; Discussion Paper No. 2017-06; International Transport Forum: Paris, France, 2017.

14. Kurtyka, K.; Pielecha, J. The evaluation of exhaust emission in RDE tests including dynamic driving conditions. Transp. Res. Procedia 2019, 40, 338-345. [CrossRef]

15. Lee, T.K.; Filipi, Z.S. Synthesis of real-world driving cycles using stochastic process and statistical methodology. Int. J. Veh. Des. 2011, 57, 17-36. [CrossRef]

16. Merkisz, J.; Lijewski, P.; Fuc, P.; Weymann, S. Exhaust emission tests from non-road vehicles conducted with the use of PEMS analyzers. Eksploat. Niezawodn. Maint. Reliab. 2013, 15, 364-368.

17. Merkisz, J.; Pielecha, J. Comparison of real driving emissions tests. IOP Conf. Ser. Mater. Sci. Eng. 2018, 421. [CrossRef]

18. Semtech-DS. On Board Vehicle Emissions Analyzer. In User Manual; Document: 9510-086, Revision: 2.01; Semtech-DS: Saline, MI, USA, 2010.

19. TSI 3090 EEPS $^{\mathrm{TM}}$ (Engine Exhaust Particle Sizer ${ }^{\mathrm{TM}}$ ). User Manual; TSI: Shoreview, MN, USA, 2008.

20. Valverde, M.V.; Giechaskiel, B.; Carriero, M. Real Driving Emissions: 2018-2019 Assessment of Portable Emissions Measurement Systems (PEMS) Measurement Uncertainty; Publications Office of the European Union: Luxembourg, 2020. [CrossRef]

21. Commission Regulation (EC) 715/2007 of the European Parliament and of the Council of 20 June 2007 on Type Approval of Motor Vehicles with Respect to Emissions from Light Passenger and Commercial Vehicles (Euro 5 and Euro 6) and on Access to Vehicle Repair and Maintenance Information, European Commission (EC). Off. J. Eur. Union 2007, L 171. Available online: http:/ / data.europa.eu/eli/reg/2007/715/oj (accessed on 10 January 2021).

22. Savitzky, A.; Golay, M.J.E. Smoothing and differentiation of data by simplified least squares procedures. Anal. Chem. 1964, 36, 1627-1639. [CrossRef]

23. BUWAL (Bundesamtfür Umwelt, Wald und Landschaft); INFRAS AG (Infrastruktur-, Umwelt- und Wirtschaftsberatung). Luftschadstoffemissionen des Strassenverkehrs 1950-2010; BUWAL-Bericht: Bern, Switzerland, 1995; p. 255.

24. COPERT 5-Manual. Available online: https://copert.emisia.com/manual/ (accessed on 1 December 2020).

25. EMEP/EEA Air Pollutant Emission Inventory Guidebook 2019. Available online: https://www.eea.europa.eu/publications/ emep-eea-guidebook-2019 (accessed on 20 December 2019).

26. Hausdorff, F. Dimension und äusseres Mass. MathematischeAnnalen 1918, 79, 157-179. [CrossRef]

27. INFRAS, AG. HandbuchfürEmissionsfaktoren des Strassenverkehrs; Version 3.1; Bern 2010. Available online: https://www. hbefa.net/e/index.html (accessed on 15 July 2019). 